Article

\title{
Numerical Simulations of the Flow Field of a Submerged Hydraulic Jump over Triangular Macroroughnesses
}

\author{
Amir Ghaderi ${ }^{1,2}\left(\mathbb{D}\right.$, Mehdi Dasineh $^{3}$, Francesco Aristodemo ${ }^{2} \mathbb{D}$ and Costanza Aricò ${ }^{4, * \mathbb{D}}$ \\ 1 Department of Civil Engineering, Faculty of Engineering, University of Zanjan, Zanjan 537138791, Iran; \\ amir_ghaderi@znu.ac.ir \\ 2 Department of Civil Engineering, University of Calabria, Arcavacata, 87036 Rende, Italy; \\ francesco.aristodemo@unical.it \\ 3 Department of Civil Engineering, Faculty of Engineering, University of Maragheh, \\ Maragheh 8311155181, Iran; mehdi.dasineh3180@gmail.com \\ 4 Department of Engineering, University of Palermo, Viale delle Scienze, 90128 Palermo, Italy \\ * Correspondence: costanza.arico@unipa.it; Tel.: +39-091-238-96516
}

Citation: Ghaderi, A.; Dasineh, M.; Aristodemo, F.; Aricò, C. Numerical Simulations of the Flow Field of a Submerged Hydraulic Jump over Triangular Macroroughnesses. Water 2021, 13, 674. https://doi.org/ 10.3390/w13050674

Academic Editor: Anis Younes

Received: 22 January 2021

Accepted: 26 February 2021

Published: 2 March 2021

Publisher's Note: MDPI stays neutral with regard to jurisdictional claims in published maps and institutional affiliations.

Copyright: (c) 2021 by the authors. Licensee MDPI, Basel, Switzerland. This article is an open access article distributed under the terms and conditions of the Creative Commons Attribution (CC BY) license (https:// creativecommons.org/licenses/by/ $4.0 /)$.

\begin{abstract}
The submerged hydraulic jump is a sudden change from the supercritical to subcritical flow, specified by strong turbulence, air entrainment and energy loss. Despite recent studies, hydraulic jump characteristics in smooth and rough beds, the turbulence, the mean velocity and the flow patterns in the cavity region of a submerged hydraulic jump in the rough beds, especially in the case of triangular macroroughnesses, are not completely understood. The objective of this paper was to numerically investigate via the FLOW-3D model the effects of triangular macroroughnesses on the characteristics of submerged jump, including the longitudinal profile of streamlines, flow patterns in the cavity region, horizontal velocity profiles, streamwise velocity distribution, thickness of the inner layer, bed shear stress coefficient, Turbulent Kinetic Energy (TKE) and energy loss, in different macroroughness arrangements and various inlet Froude numbers $\left(1.7<F r_{1}<9.3\right)$. To verify the accuracy and reliability of the present numerical simulations, literature experimental data were considered.
\end{abstract}

Keywords: submerged hydraulic jump; triangular macroroughnesses; TKE; bed shear stress coefficient; velocity; FLOW-3D model

\section{Introduction}

Hydraulic jumps with intense turbulent mixing and air bubble entrainment are regarded as a change process from supercritical to subcritical flow [1]. Free and submerged hydraulic jumps are usually suitable for energy loss under hydraulic structures such as gates, spillways and weirs. The characteristics of hydraulic jumps on the smooth bed have been widely studied [2-9]. Several experimental and numerical studies have been performed on the free and submerged hydraulic jumps over macroroughnesses to foresee how the roughness elements of the bed affect the characteristics of hydraulic jumps compared to the smooth bed. Ead and Rajaratnam [10] investigated the properties of hydraulic jump on sinusoidal macroroughnesses and normalized the water surface profile and discharge with non-dimensional analysis. Tokyay et al. [11] observed that the jump length ratio and energy loss over two sinusoidal macroroughnesses were $35 \%$ smaller and $6 \%$ higher than a smooth bed, respectively. Abbaspour et al. [12] studied the properties of a hydraulic jump over six sinusoidal macroroughnesses. The results stated that the tailwater depth and jump length were lower than the smooth bed and the Froude number had a great impact on the jump length. Shafai-Bejestan and Neisi [13] investigated the effects of lozenge macroroughnesses on the hydraulic jump. The results showed that the use of lozenge macroroughnesses reduced the tailwater depth and jump length compared with the smooth bed. Izadjoo and Shafai-Bejestan [14] studied hydraulic jumps on various 
trapezoidal macroroughnesses. They observed that the shear stress coefficient was over ten times larger than that on the smooth bed, and the jump length decreased by $50 \%$. Nikmehr and Aminpour [15] investigated the properties of a hydraulic jump over macroroughnesses with trapezoidal blocks using the Flow-3D model Version 11.2 [16]. The results stated that increasing the height and the distance of the macroroughnesses, the velocity decreases near the bed as well as the shear stress coefficient. Ghaderi et al. [17] studied the free and submerged hydraulic jump characteristics over different shapes of macroroughness (triangular, square and semi-oval). The results stated that the shear stress coefficient, energy loss, the submerged depth, the tailwater depth and the relative length of jump in free and submerged jumps increase with the increasing Froude number. The highest shear stress and energy loss in the free and submerged jumps occurred in the presence of a triangular macroroughness. Elsebaie and Shabayek [18] studied the properties of hydraulic jumps on five shapes of macroroughnesses (triangular, trapezoidal, sinusoidal with two side slopes and rectangular). The result showed that energy loss for all macroroughnesses was more than 15 times that on a smooth bed. Samadi-Boroujeni et al. [19] investigated the hydraulic jump on six triangular macroroughnesses of various angles and showed that the triangular macroroughnesses reduce the jump length and increase the energy loss and the bed shear stress coefficient compared to the smooth bed. Ahmed et al. [20] investigated the submerged hydraulic jump properties on a smooth bed and triangular macroroughnesses. The results stated that submerged depth and jump length decreased if compared to the smooth bed. Table 1 lists the details of past experimental and numerical studies on hydraulic jumps presented by other researchers.

Table 1. Main characteristics of some past experimental and numerical studies on hydraulic jumps.

\begin{tabular}{|c|c|c|c|c|c|}
\hline Reference & $\begin{array}{l}\text { Shape Bed-Channel Type- } \\
\text { Jump Type }\end{array}$ & $\begin{array}{l}\text { Channel } \\
\text { Dimension (m) }\end{array}$ & Roughness (mm) & $F r_{1}$ & $\begin{array}{l}\text { Investigated Flow } \\
\text { Properties }\end{array}$ \\
\hline $\begin{array}{l}\text { Ead and } \\
\text { Rajaratnam [10] }\end{array}$ & $\begin{array}{l}\text { - Smooth and rough beds } \\
\text { - Rectangular channel } \\
\text { - Free jump }\end{array}$ & $\begin{array}{l}\mathrm{CL}^{1}=7.60 \\
\mathrm{CW}^{2}=0.44 \\
\mathrm{CH}^{3}=0.60\end{array}$ & $\begin{array}{c}\text { - Corrugated sheets } \\
\left(\mathrm{RH}^{4}=13 \text { and } 22\right)\end{array}$ & $4-10$ & $\begin{array}{l}\text { - Upstream and tailwater } \\
\text { depths } \\
\text { - Jump length } \\
\text { - Roller length } \\
\text { - Velocity } \\
\text { - Water surface profile }\end{array}$ \\
\hline Tokyay et al. [11] & $\begin{array}{l}\text { - Smooth and rough beds } \\
\text { - Rectangular channel } \\
\text { - Free jump }\end{array}$ & $\begin{array}{l}\mathrm{CL}=10.50 \\
\mathrm{CW}=0.253 \\
\mathrm{CH}=0.432\end{array}$ & $\begin{array}{l}\text { - Two sinusoidal } \\
\text { corrugated } \\
\text { (RH = } 10 \text { and 13) }\end{array}$ & $5-12$ & $\begin{array}{l}\text { - Depth ratio } \\
\text { - Jump length } \\
\text { - Energy loss }\end{array}$ \\
\hline $\begin{array}{l}\text { Izadjoo and } \\
\text { Shafai-Bejestan [14] }\end{array}$ & $\begin{array}{l}\text { - Smooth and rough beds } \\
\text { - Two rectangular } \\
\text { - channel } \\
\text { - Free jump }\end{array}$ & $\begin{array}{l}\mathrm{CL}=1.2,9 \\
\mathrm{CW}=0.25,0.50 \\
\mathrm{CH}=0.40\end{array}$ & $\begin{array}{l}\text { Baffle with } \\
\text { trapezoidal cross } \\
\text { section } \\
\text { (RH: } 13 \text { and } 26)\end{array}$ & $6-12$ & $\begin{array}{l}\text { - Upstream and tailwater } \\
\text { depths } \\
\text { - Jump length } \\
\text { - Velocity } \\
\text { - Bed shear stress } \\
\text { coefficient }\end{array}$ \\
\hline Abbaspour et al. [12] & $\begin{array}{l}\text { - Horizontal bed with slope } \\
0.002 \\
\text { - Rectangular } \\
\text { channel—smooth and } \\
\text { rough beds } \\
\text { - Free jump }\end{array}$ & $\begin{array}{l}\mathrm{CL}=10 \\
\mathrm{CW}=0.25 \\
\mathrm{CH}=0.50\end{array}$ & $\begin{array}{l}\text { - Sinusoidal bed } \\
\text { (RH = 15,20, } 25 \\
\text { and 35) }\end{array}$ & $3.80-8.60$ & $\begin{array}{l}\text { - Water surface profile } \\
\text { - Depth ratio } \\
\text { - Jump length } \\
\text { - Energy loss } \\
\text { - Velocity profiles } \\
\text { - Bed shear stress } \\
\text { coefficient }\end{array}$ \\
\hline $\begin{array}{l}\text { Shafai-Bejestan and } \\
\text { Neisi [13] }\end{array}$ & $\begin{array}{l}\text { - Smooth and rough beds } \\
\text { - Rectangular channel } \\
\text { - Free jump }\end{array}$ & $\begin{array}{l}\mathrm{CL}=7.50 \\
\mathrm{CW}=0.35 \\
\mathrm{CH}=0.50\end{array}$ & Lozenge bed & $4.50-12$ & $\begin{array}{l}\text { - Sequent depth } \\
\text { - Jump length }\end{array}$ \\
\hline
\end{tabular}


Table 1. Cont.

\begin{tabular}{|c|c|c|c|c|c|}
\hline Reference & $\begin{array}{l}\text { Shape Bed-Channel Type- } \\
\text { Jump Type }\end{array}$ & $\begin{array}{l}\text { Channel } \\
\text { Dimension (m) }\end{array}$ & Roughness (mm) & $F r_{1}$ & $\begin{array}{l}\text { Investigated Flow } \\
\text { Properties }\end{array}$ \\
\hline $\begin{array}{l}\text { Elsebaie and } \\
\text { Shabayek [18] }\end{array}$ & $\begin{array}{l}\text { - Smooth and rough beds } \\
\text { - Rectangular channel } \\
\text { - With side slopes of } \\
45 \text { degrees for two } \\
\text { trapezoidal and triangular } \\
\text { macroroughnesses and of } \\
60 \text { degrees for other } \\
\text { trapezoidal } \\
\text { macroroughnesses } \\
\text { - Free jump }\end{array}$ & $\begin{array}{l}\mathrm{CL}=9 \\
\mathrm{CW}=0.295 \\
\mathrm{CH}=0.32\end{array}$ & $\begin{array}{l}\text { - Sinusoidal } \\
\text { - Triangular } \\
\text { - Trapezoidal with } \\
\text { two side } \\
\text { - Rectangular } \\
\text { - }(\mathrm{RH}=18 \text { and } \\
\text { corrugation } \\
\text { wavelength }=65)\end{array}$ & 50 & $\begin{array}{l}\text { - Water surface profile } \\
\text { - Sequent depth } \\
\text { - Jump length } \\
\text { - Bed shear stress } \\
\text { coefficient }\end{array}$ \\
\hline $\begin{array}{l}\text { Samadi-Boroujeni } \\
\text { et al. [19] }\end{array}$ & $\begin{array}{l}\text { - Rectangular channel } \\
\text { - Smooth and rough beds } \\
\text { - Free jump }\end{array}$ & $\begin{array}{l}\mathrm{CL}=12 \\
\mathrm{CW}=0.40 \\
\mathrm{CH}=0.40\end{array}$ & $\begin{array}{l}\text { - Six triangular } \\
\text { corrugated } \\
(\mathrm{RH}=2.5)\end{array}$ & $6.10-13.10$ & $\begin{array}{l}\text { - Water surface profile } \\
\text { - Sequent depth } \\
\text { - Jump length } \\
\text { - Energy loss } \\
\text { - Velocity profiles } \\
\text { - Bed shear stress } \\
\text { coefficient }\end{array}$ \\
\hline Ahmed et al. [20] & $\begin{array}{l}\text { - Smooth and rough beds } \\
\text { - Rectangular channel } \\
\text { - Submerged jump }\end{array}$ & $\begin{array}{l}\mathrm{CL}=24.50 \\
\mathrm{CW}=0.75 \\
\mathrm{CH}=0.70\end{array}$ & $\begin{array}{l}\text { - Triangular } \\
\text { corrugated sheet } \\
(\mathrm{RH}=40)\end{array}$ & $1.68-9.29$ & $\begin{array}{l}\text { - Conjugated and } \\
\text { tailwater depths } \\
\text { - Submerged ratio } \\
\text { - Deficit depth } \\
\text { - Relative jump length } \\
\text { - Jump length } \\
\text { - Relative roller jump } \\
\text { length } \\
\text { - Jump efficiency } \\
\text { - Bed shear stress } \\
\text { coefficient }\end{array}$ \\
\hline $\begin{array}{l}\text { Nikmehr and } \\
\text { Aminpour [15] }\end{array}$ & $\begin{array}{l}\text { - Horizontal bed with slope } \\
0.002 \\
\text { - Rectangular channel } \\
\text { - Rough bed } \\
\text { - Free jump }\end{array}$ & $\begin{array}{l}\mathrm{CL}=12 \\
\mathrm{CW}=0.25 \\
\mathrm{CH}=0.50\end{array}$ & $\begin{array}{l}\text { - Trapezoidal blocks } \\
(\mathrm{RH}=2,3 \text { and } 4)\end{array}$ & $5.01-13.70$ & $\begin{array}{l}\text { - Water surface profile } \\
\text { - Sequent depth } \\
\text { - Jump length } \\
\text { - Roller length } \\
\text { - Velocity }\end{array}$ \\
\hline Ghaderi et al. [17] & $\begin{array}{l}\text { - Smooth and rough beds } \\
\text { - Rectangular channel } \\
\text { - Free and submerged jump }\end{array}$ & $\begin{array}{l}\mathrm{CL}=4.50 \\
\mathrm{CW}=0.75 \\
\mathrm{CH}=0.70\end{array}$ & $\begin{array}{l}\text { - Triangular, square } \\
\text { and semi-oval } \\
\text { macroroughnesses } \\
(\mathrm{RH}=40 \text { and } \\
\text { distance of } \\
\text { roughness of I = 40, } \\
80,120,160 \text { and 200) }\end{array}$ & $1.70-9.30$ & $\begin{array}{l}\text { - Horizontal velocity } \\
\text { distributions } \\
\text { - Bed shear stress } \\
\text { coefficient } \\
\text { - Sequent depth ratio and } \\
\text { submerged depth ratio } \\
\text { - Jump length } \\
\text { - Energy loss }\end{array}$ \\
\hline Present study & $\begin{array}{l}\text { Rectangular channel } \\
\text { Smooth and rough beds } \\
\text { Submerged jump }\end{array}$ & $\begin{array}{l}\mathrm{CL}=4.50 \\
\mathrm{CW}=0.75 \\
\mathrm{CH}=0.70\end{array}$ & $\begin{array}{l}\text { - Triangular } \\
\text { macroroughnesses } \\
(\mathrm{RH}=40 \text { and } \\
\text { distance of } \\
\text { roughness of } \mathrm{I}=40, \\
80,120,160 \text { and 200) }\end{array}$ & $1.70-9.30$ & $\begin{array}{l}\text { - Longitudinal profile of } \\
\text { streamlines } \\
\text { - Flow patterns in the } \\
\text { cavity region } \\
\text { - Horizontal velocity } \\
\text { profiles } \\
\text { - Streamwise velocity } \\
\text { distribution } \\
\text { - Bed shear stress } \\
\text { coefficient } \\
\text { - TKE } \\
\text { - Thickness of the inner } \\
\text { layer } \\
\text { - Energy loss }\end{array}$ \\
\hline
\end{tabular}

$\mathrm{CL}^{1}$ : channel length, $\mathrm{CW}^{2}$ : channel width, $\mathrm{CH}^{3}$ : channel height, $\mathrm{RH}^{4}$ : roughness height.

The major part of the previously discussed investigations are based on laboratory approaches and investigate how sinusoidal, lozenge, trapezoidal, square, rectangular and triangular macroroughnesses affect some free and submerged hydraulic jumps characteristics, e.g., conjugate depths, submerged depth, jump length, energy loss and bed shear stress coefficient. Moreover, with reference to a previous published paper about hydraulic jumps on different shapes of macroroughness by the authors [17], it was observed that the triangular macroroughnesses have the highest bed shear stress coefficient and energy loss and 
also have the lowest submerged depth, tailwater depth and jump length compared to other rough shapes, i.e., square and semi-oval, and a smooth bed. Hence, in the present paper, using the triangular macroroughnesses (for different $T / \mathrm{I}$ ratios with a constant roughness height of $T=4 \mathrm{~cm}$ and a distance of triangular roughness of $I=4,8,12,16$ and $20 \mathrm{~cm}$ ), specific studies such as the flow patterns in the cavity region, turbulent kinetic energy (TKE) and streamwise velocity distribution are required. Computational fluid dynamics (CFD) methods arise as an important tool to undertake the modeling process of complex flows such as the free and submerged hydraulic jumps [21] and the characteristics of a submerged hydraulic jump can be accurately predicted utilizing CFD simulations [22,23].

The present paper initially presents the main characteristics of a submerged hydraulic jump, the input parameters for the numerical model and a reference experimental investigation by Ahmed et al. [20], reported for validation purposes. Furthermore, this study will investigate characteristics such as the longitudinal profile of streamlines, flow patterns in the cavity region, horizontal velocity profiles, thickness of the inner layer, bed shear stress coefficient, TKE and energy loss.

\section{Submerged Hydraulic Jump}

The submerged hydraulic jump happens when the tailwater depth is larger than the sequent depth of the pre-existing free jump; in this state, the jump moves upstream and air entrainment reduces $[24,25]$. Figure 1 presents a schematic view of a hydraulic jump with effective hydraulic parameters on the triangular macroroughnesses. In this view, $d$ is the gate opening, $T$ and $I$ are the height and distance of triangular roughness, $y_{1}, y_{2}$ and $y_{3}, y_{4}$ are supercritical, subcritical of the free jump depth and submerged, tailwater of the submerged jump depth, respectively.

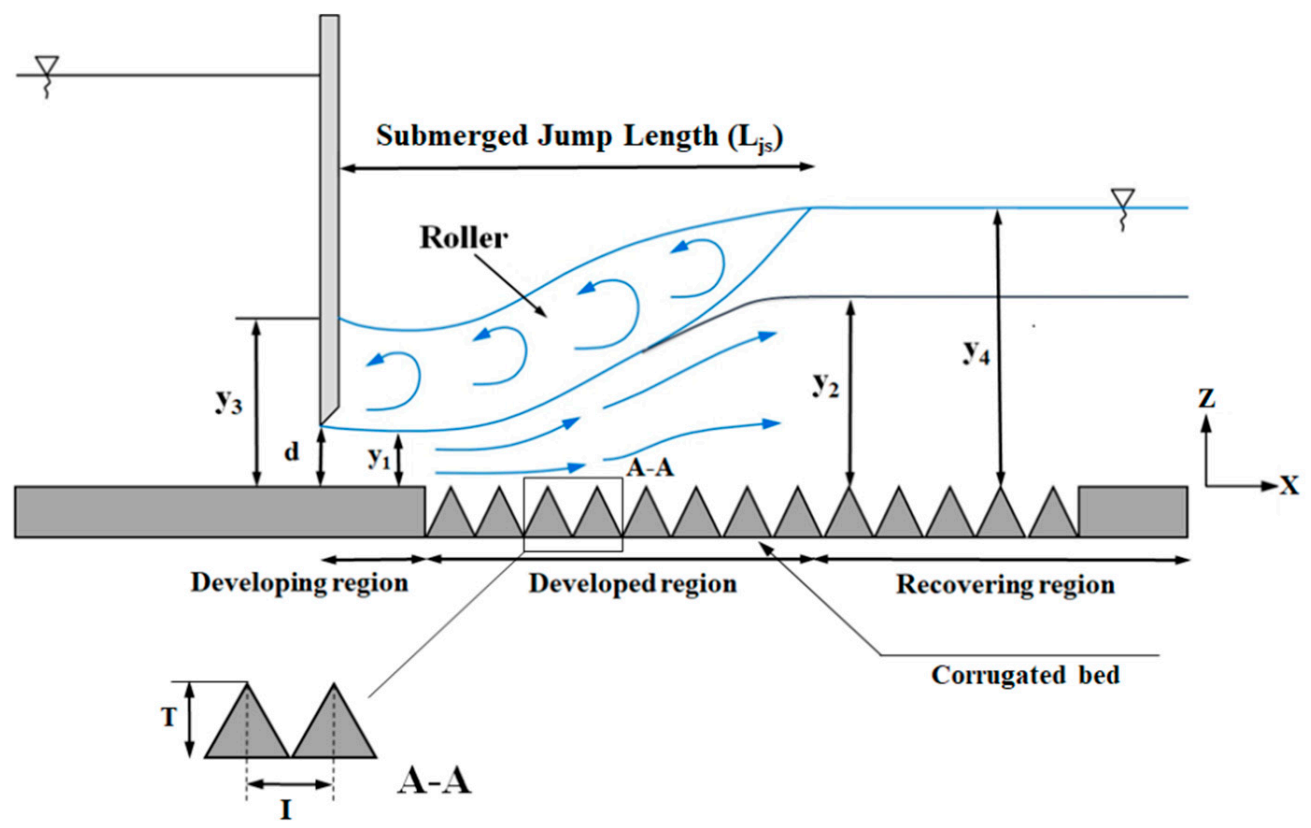

Figure 1. Definition sketch of a submerged hydraulic jump at triangular macroroughnesses.

According to Figure 1, it is possible to define three regions in the submerged hydraulic jump: the developing, the developed and the recovering regions [26]. Whilst the developing region occupies as far as the potential-core zone and involves a supercritical zone with wall jet properties, the developed region extends throughout the length of the roller of the horizontal axis $\left(L_{j s}\right)$, where a big counter-clockwise circulating free surface roller dissipates the hydraulic energy, beyond which the recovering region begins and involves a subcritical region. 


\section{Materials and Methods}

\subsection{Input Parameters for Numerical Models}

Simulations were implemented in the Froude number range of 1.7-9.3, with submergence factors $(S)$ from 0.26 to 0.50 , a fixed gate opening $(d)$ of $5 \mathrm{~cm}$, a constant macroroughnesses height of $4 \mathrm{~cm}$, and different $T / \mathrm{I}$.

In Table $2, u_{1}$ is inlet velocity, $g$ and $v$ are gravity acceleration and water kinematic viscosity, respectively. The value of $S$ is calculated by Equation (1) [24]:

$$
S=\frac{y_{4}-y_{2}}{y_{2}}
$$

Table 2. Effective parameters in the numerical model.

\begin{tabular}{|c|c|c|c|c|c|c|c|c|c|}
\hline Bed Type & $\underset{(1 / s)}{Q}$ & $\begin{array}{c}I \\
(\mathrm{~cm})\end{array}$ & $\begin{array}{c}T \\
(\mathrm{~cm})\end{array}$ & $\begin{array}{c}d \\
(\mathrm{~cm})\end{array}$ & $\begin{array}{c}y_{1} \\
(\mathrm{~cm})\end{array}$ & $\begin{array}{c}y_{4} \\
(\mathrm{~cm})\end{array}$ & $F r_{1}=u_{1} /\left(g y_{1}\right)^{0.5}$ & $S$ & $R e_{1}=\left(u_{1} y_{1}\right) / v$ \\
\hline Smooth & 30,45 & - & - & 5 & $1.62-3.83$ & $9.64-32.10$ & $1.7-9.3$ & $0.26-0.50$ & $39,884-59,825$ \\
\hline Triangular macroroughnesses & 30,45 & $4,8,12,16,20$ & 4 & 5 & $1.62-3.84$ & $6.82-30.08$ & $1.7-9.3$ & $0.21-0.44$ & $39,884-59,825$ \\
\hline
\end{tabular}

The subcritical depth of the free jump can be calculated by the Bélanger equation, as explained by Chow [27]:

$$
y_{2}=\frac{y_{1}}{2}\left[\sqrt{\left(1+8 F r_{1}^{2}\right)}-1\right]
$$

\subsection{Experimental Model}

To confirm the performance and reliability of the present simulations, reference experimental data by Ahmed et al. [20] are considered as a benchmark solution for some of the basic parameters of submerged hydraulic jump on smooth bed and macroroughnesses, including a submerged ratio and tailwater ratio $\left(y_{3} / y_{1}\right.$ and $\left.y_{4} / y_{1}\right)$. For these experiments, a flume with length, width and depth of $24.5,0.75$ and $0.7 \mathrm{~m}$, respectively, was used (see Figure 2). The discharge and water depths were evaluated through an ultrasonic flow meter which was specified at the supply lines and a point-gauge, respectively. A gate with a horizontal basin was used to develop the required supercritical flow and initial depth of the hydraulic jumps. Downstream water depth was controlled by a tailgate to form hydraulic jumps over the rigid bed, and then, the water flowed to the by-pass channel (for more details, see Ahmed et al. [20]).

Although the length of the experimental flume was $24.5 \mathrm{~m}$, in the present study, the length of the flume in the numerical runs was set equal to $4.5 \mathrm{~m}$, to decrease the computational effort decreasing the overall number of the computational cells.

Table 3 shows the main flow variables for the numerical and physical models.

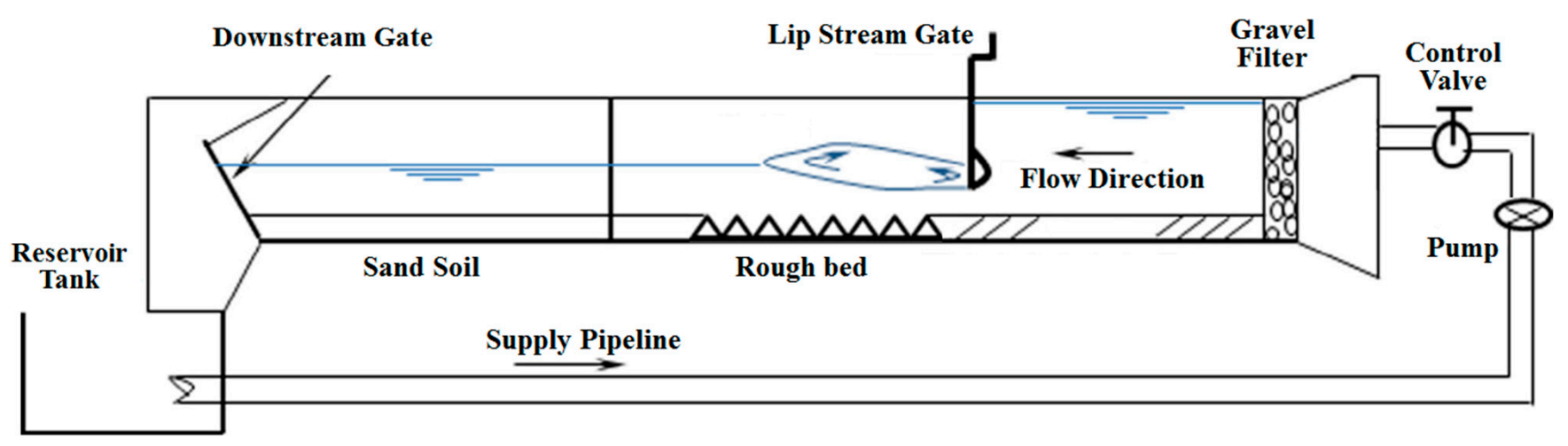

Figure 2. Longitudinal profile of the experimental flume (Ahmed et al. [20]). 
Table 3. Main flow variables for the numerical and physical models (Ahmed et al. [20]).

\begin{tabular}{ccccccc}
\hline Models & Bed Type & $\boldsymbol{Q} \mathbf{( 1 / s )}$ & $\boldsymbol{d}(\mathbf{c m})$ & $\boldsymbol{y}_{\mathbf{1}}(\mathbf{c m})$ & $\boldsymbol{u}_{\mathbf{1}}(\mathbf{m} / \mathbf{s})$ & $\boldsymbol{F} \boldsymbol{r}_{\mathbf{1}}$ \\
\hline \multirow{3}{*}{ Numerical and Physical } & Smooth & 45 & 5 & $1.62-3.83$ & $1.04-3.70$ & $1.7-9.3$ \\
& $T / I=0.5$ & 45 & 5 & $1.61-3.83$ & $1.05-3.71$ & $1.7-9.3$ \\
& $T / I=0.25$ & 45 & 5 & $1.60-3.84$ & $1.04-3.71$ & $1.7-9.3$ \\
\hline
\end{tabular}

\subsection{CFD Analysis}

Generally, the application of computational methods is essential for the prediction of entrained air in free surface/two-phase flows. The hydraulic jumps are specified by an extremely turbulent flow zone with a significant amount of entrained air. Therefore, numerical simulations of two-phase flow involving a hydraulic jump were here performed with the help of the commercial CFD software FLOW-3D ${ }^{\circledR}$ [16]. The FLOW-3D uses the finite volume method in a Cartesian, staggered grid to solve the Reynolds' average NavierStokes (RANS equations. The governing equations are briefly described in tensor notations. Assuming incompressible fluid, the mass conservation equation is expressed as

$$
\frac{\partial u_{i}}{\partial x_{i}}=0
$$

The momentum conservation equations (Navier-Stokes equations) are:

$$
\rho \frac{\partial u_{i}}{\partial t}+\rho u_{j} \frac{\partial u_{i}}{\partial x_{j}}=-\frac{\partial p}{\partial x_{i}}+\frac{\partial t_{j i}}{\partial x_{j}}
$$

Here, $u_{i}$ and $x_{i}$ are velocity and position vectors, $t$ is the time, $p$ and $\rho$ denotes the pressure and fluid density and $t_{i j}$ refers to the viscous stress tensor, expressed by

$$
t_{i j}=2 \mu s_{i j}
$$

where $\mu$ is molecular viscosity and $s_{i j}$ refers to the strain-rate tensor, defined as

$$
s_{i j}=\frac{1}{2}\left(\frac{\partial u_{i}}{\partial x_{j}}-\frac{\partial u_{j}}{\partial x_{i}}\right)
$$

Note that $s_{i j}=s_{j i}$, so that $t_{j i}=t_{i j}$ for simple viscous fluids [28]. The FLOW-3D ${ }^{\circledR}$ utilizes an advanced algorithm for tracking free-surface flows, called volume of fluid (VOF), and is developed by Hirt and Nichols [29]. The VOF equation is written by the Equation (7):

$$
\frac{\partial F}{\partial t}+\frac{1}{V_{F}}\left[\frac{\partial\left(F A_{x} u\right)}{\partial x}+\frac{\partial\left(F A_{y} v\right)}{\partial y}+\frac{\partial\left(F A_{z} w\right)}{\partial z}\right]=0
$$

Here, $F$ denotes the fraction function. In particular, if a cell is empty, then $F=0$, and if a cell is full, then $F=1[16,30,31]$. The free surface is determined at a position related to intermediate amounts of $F$ (usually $F=0.5$, but another intermediate amount may be determined by the user).

\subsection{Turbulence Model}

The Reynolds decomposition is the main tool needed for the extraction of the RANS equations from the instantaneous Navier-Stokes equations. The Reynolds decomposition simplifies the Navier-Stokes equations (see Equation (4)) by the separation of the flow variable (like velocity $u$ ) into the mean (time-averaged) component $(\bar{u})$ and the fluctuating component $\left(u^{\prime}\right)$. Thus, we can replace the Navier-Stokes Equation (4) and obtain the average Navier-Stokes equations [32]. The obtained equation includes a nonlinear term that gives rise to turbulence defined as the Reynolds stresses tensor. The Boussinesq 
hypothesis is used to relate the Reynolds stresses tensor $\left(-\rho \overline{u_{i}^{\prime} u_{j}^{\prime}}\right)$ to the mean velocity gradients using an eddy viscosity by the following equation:

$$
-\rho \overline{u_{i}^{\prime} u_{j}^{\prime}}=\varepsilon\left[\frac{1}{2}\left(\frac{\partial U_{i}}{\partial x_{j}}-\frac{\partial U_{j}}{\partial x_{i}}\right)\right]-\frac{2}{3} k \delta_{i j}
$$

Here, $U_{i}$ denotes the mean velocity component in a Cartesian coordinate system, $x_{i}$ is the Cartesian space $(i, j, k), \varepsilon_{i j}$ is the eddy viscosity tensor, $\delta_{i j}$ and $k$ are the Kronecker delta and the turbulent kinetic energy, respectively [29]. In present study, the desired turbulence model was $R N G k-\varepsilon$, as suggested in Flow Science, Inc. (New York, NY, USA) [16]. The RNG $k-\varepsilon$ is similar to the standard $k-\varepsilon$ model even if it contains some refinements. In particular, the RNG $k-\varepsilon$ turbulence model has an additional term in its $\varepsilon$ equation (see successive Equation (12)) that improves the accuracy for quickly strained and swirling flows and also have good accuracy based on the results of numerical investigations by Carvalho et al. [33], Bayon et al. [34], Daneshfaraz et al. [35], Ghaderi and Abbasi [36] and Ghaderi et al. [37,38]. This model was proposed by Yakhot and Orszag [39] and represents a modified version of the $k-\varepsilon$ standard model.

The adopted turbulence scheme is a two-equation model. In particular, the first equation (Equation (9)), which is called turbulent kinetic energy $(k)$, expresses the energy in turbulence. The second equation (Equation (10)), which determines the rate of kinetic energy dissipation, is the turbulent dissipation rate $(\varepsilon)$. These equations are presented as follows:

$$
\begin{gathered}
\frac{\partial(\rho k)}{\partial t}+\frac{\partial\left(\rho k u_{i}\right)}{\partial x_{i}}=\frac{\partial}{\partial x_{j}}\left[\alpha_{k} \mu_{e f f} \frac{\partial k}{\partial x_{j}}\right]+G_{k}-G_{B}-\rho \varepsilon-Y_{M}+S_{k} \\
\frac{\partial(\rho \varepsilon)}{\partial t}+\frac{\partial\left(\rho \varepsilon u_{i}\right)}{\partial x_{i}}=\frac{\partial}{\partial x_{j}}\left[\alpha_{\varepsilon} \mu_{e f f} \frac{\partial \varepsilon}{\partial x_{j}}\right]+C_{1 \varepsilon} \frac{\varepsilon}{k}\left(G_{k}+C_{3 \varepsilon} G_{b}\right)-C_{2 \varepsilon} \rho \frac{\varepsilon^{2}}{k}-R_{\varepsilon}+S_{\varepsilon}
\end{gathered}
$$

Here, $G_{k}$ refers to the generation of turbulent kinetic energy caused by the average velocity gradient, $G_{b}$ denotes the generation of turbulent kinetic energy caused by buoyancy, while $S_{k}$ and $S_{\varepsilon}$ are source terms. $\alpha_{k}$ and $\alpha_{\varepsilon}$ are inverse effective Prandtl numbers for $k$ and $\varepsilon$, respectively. $\mu_{\text {eff }}$ is the effective viscosity $\mu_{\text {eff }}=\mu+\mu_{t}$, being the eddy viscosity.

For the above equation [40-42]:

$$
\begin{gathered}
R_{\varepsilon}=\frac{C_{\mu} \rho \eta^{3}\left(1-\eta / \eta_{0}\right) \varepsilon^{2}}{k\left(1+\beta \eta^{3}\right)} \\
\mu_{t}=\frac{\rho C_{\mu} k^{2}}{\varepsilon}
\end{gathered}
$$

The constant values for this model are [39]:

$C_{\mu}=0.0845, C_{1 \varepsilon}=1.42, C_{2 \varepsilon}=1.68, C_{3 \varepsilon}=1.0, \sigma_{k}=0.7194, \sigma_{\varepsilon}=0.7194, \eta_{0}=4.38$ and $\beta=0.012$.

\subsection{Boundary Conditions in the Computational Domain}

According to Figure 3, the discharge flow rate (Q) equal to the experimental flow exit discharge as the inlet boundary condition, a pressure $(\mathrm{P})$ corresponding to the tailwater depth as the downstream boundary condition were set. The lower bottom $(Z)$ and both boundary lateral sides behave as rigid wall $(W)$. No-slip conditions are expressed as zero tangential and normal velocities $(u=v=w=0$, where $u, v$ and $w$ are the velocities in the directions $x, y$ and $z$, respectively) that were used at the wall boundaries. This boundary condition implies a wall-law velocity profile (the average velocity of turbulent flow at a certain point is proportional to the logarithm of the distance from that point to the boundary of the fluid zone) [16]. For the upper boundary, the atmospheric pressure boundary condition due to the flow to enter and leave the domain as null von Neumann conditions was imposed to all variables except for pressure, which is set to zero. Symmetry 
(S) was used at the inner boundary conditions as well. Figure 3 shows the boundary conditions governing the simulations.

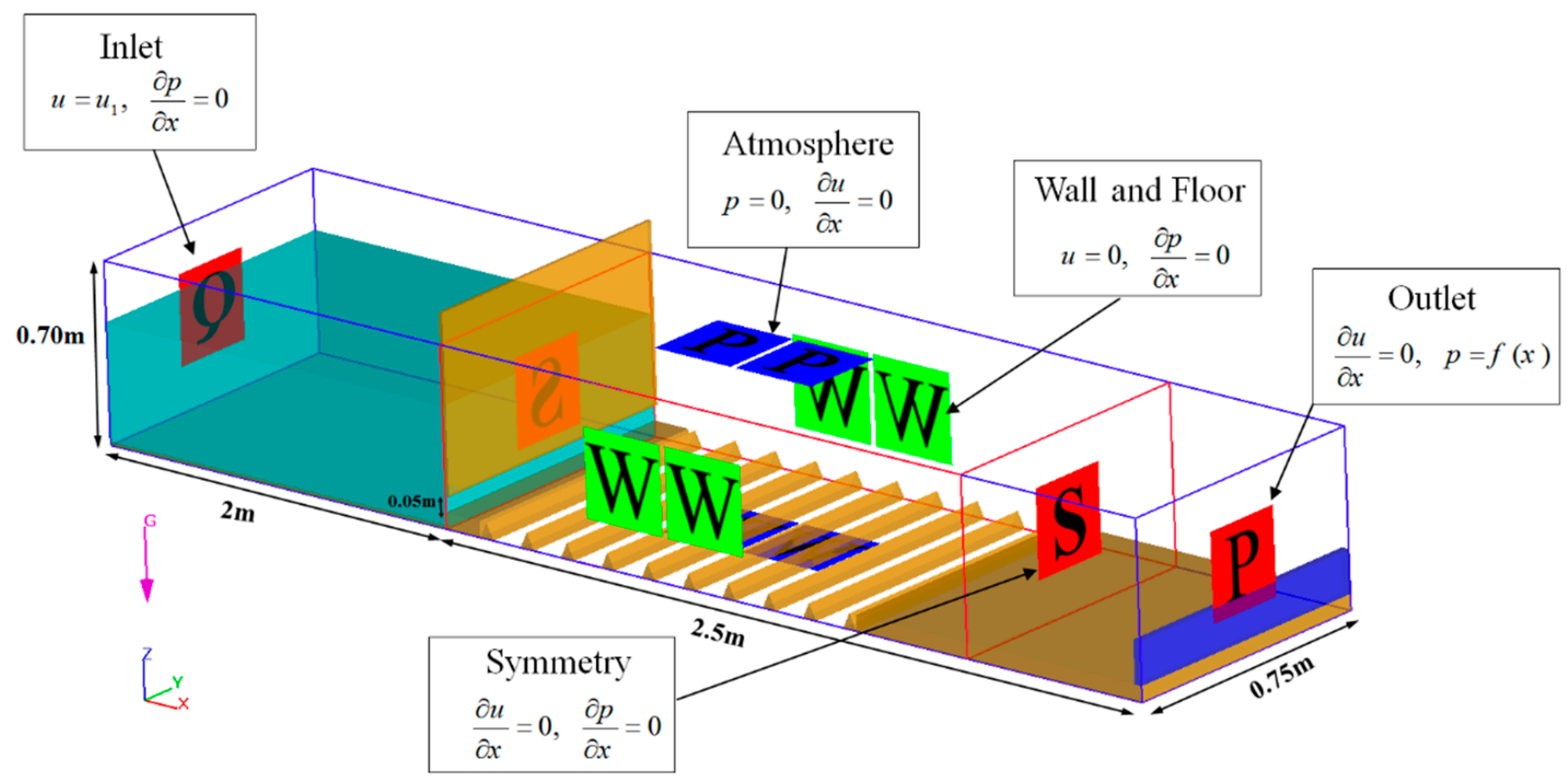

Figure 3. The boundary conditions governing the simulations.

\subsection{Computational Grid and Grid Convergence Analysis}

In the present study, the spatial domain meshed with the help of a structured rectangular hexahedral mesh with two mesh blocks was built. In particular, the above mesh blocks include a mesh block for the entire spatial domain and a nested mesh block with refined cells for the area of interest (see Figure 4). By using the Grid Convergence Index (GCI) (specified for the computed $y_{3} / y_{1}$ ratio at $F r_{1}=4.5$ obtained from the numerical solution), which is a recommended method for evaluating the discretization error, three various computational meshes were applied to choose the appropriate one $[17,34,38,43]$. The analysis was performed according to the Richardson extrapolation method [44]. To investigate the effect of the grid size on the accuracy of the results, three meshes were used with fine, medium, and coarse cells, containing 1,285,482 and 2,908,596, and 4,624,586 cells, respectively. Table 4 shows some characteristics of the computational grids.

The fine-grid convergence index is expressed as [43]

$$
G C I_{32}^{\text {fine }}=\frac{1.25\left|E_{32}\right|}{r_{32}^{p}-1}
$$

Here, $E_{32}=\left(f_{s 2}-f_{s 3}\right) / f_{s 2}$ refers to the relative error between the medium and fine grids, $f_{s 2}$ and $f_{s 3}$ are medium and fine grid solutions for $y_{3} / y_{1}$, respectively, and $K$ denotes the local order of accuracy. For the three-grid solutions, $K$ is presented as follows:

$$
K=\frac{1}{\ln r_{32}} \ln \frac{\left(r_{32}^{p}-1\right) e_{21}}{\left(r_{21}^{p}-1\right) e_{32}}
$$

where $e_{21}=f_{s 2}-f_{s 1}, e_{32}=f_{s 3}-f_{s 2}$ and $r_{21}=G_{2} / G_{1}$ are the grid refinement factor between the medium and coarse grids, and $r_{32}=G_{3} / G_{2}$ is the grid refinement factor between the fine and medium grids. The value of $f_{s 1}$ represents the coarse grid solution and $G_{1}, G_{2}$ and $G_{3}$ are the abbreviations of grids. For the three-grid comparisons, $G_{3}<G_{2}<G_{1}$. Table 5 summarizes the numerical results of the mesh convergence analysis in the present study. 
According to this table, the amounts of $\mathrm{GCI}_{21}$ and $\mathrm{GCI}_{32}$ are the relative change from medium to coarse and from coarse to medium mesh, respectively.

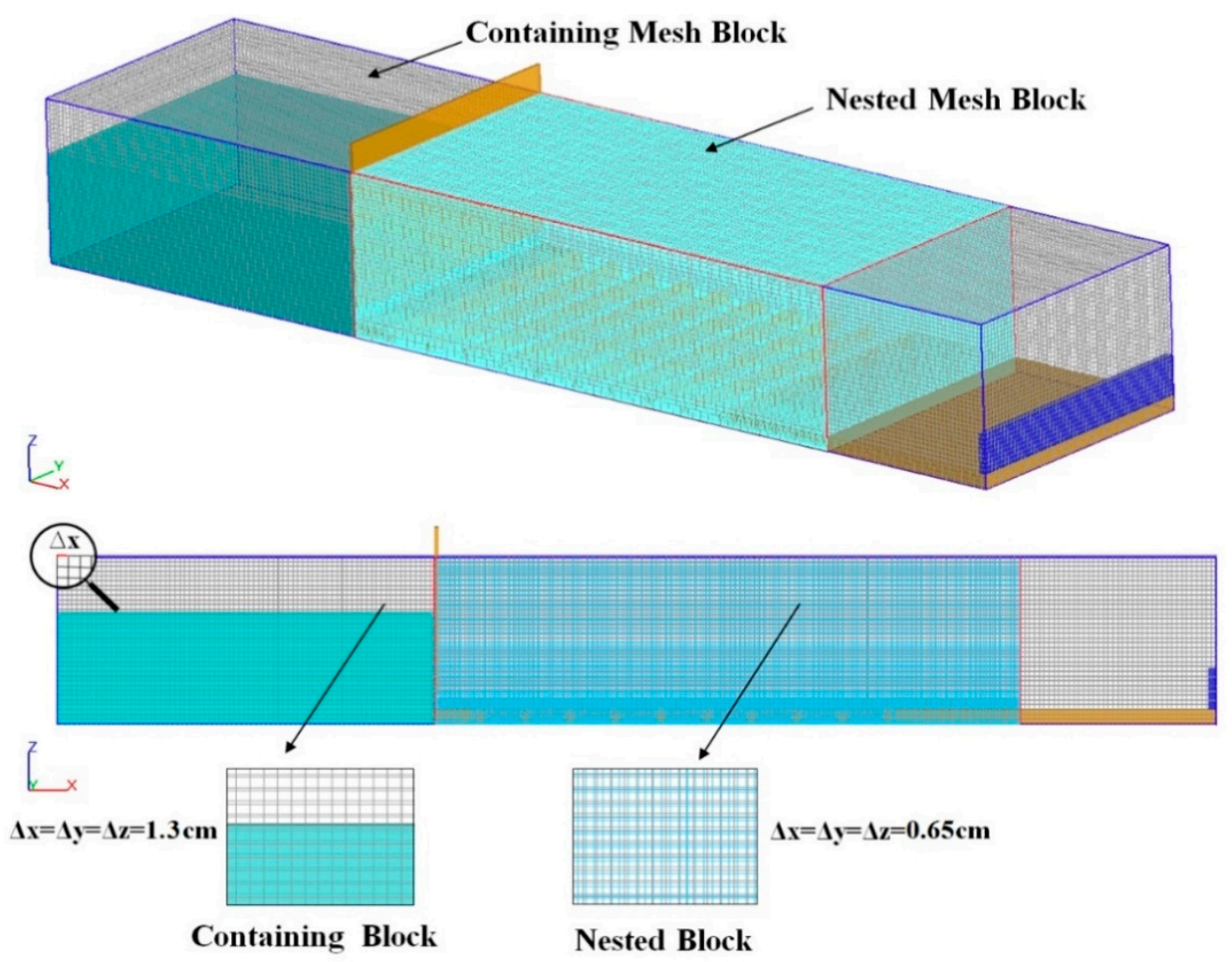

Figure 4. Sketch of mesh setup.

Table 4. Characteristics of the computational grids.

\begin{tabular}{ccc}
\hline Mesh & Nested Block Cell Size (cm) & Containing Block Cell Size (cm) \\
\hline 1 & 0.55 & 1.10 \\
2 & 0.65 & 1.30 \\
3 & 0.85 & 1.70 \\
\hline
\end{tabular}

Table 5. The numerical results of mesh convergence analysis.

\begin{tabular}{cc}
\hline Parameters & Amounts \\
\hline$f_{s 1}(-)$ & 7.15 \\
$f_{s 2}(-)$ & 6.88 \\
$f_{s 3}(-)$ & 6.19 \\
$K(-)$ & 5.61 \\
$E_{32}(\%)$ & 10.02 \\
$E_{21}(\%)$ & 3.77 \\
$G C I_{21}(\%)$ & 3.03 \\
$G C I_{32}(\%)$ & 3.57 \\
$G C I_{32} / r^{p} G C I_{21}$ & 0.98 \\
\hline
\end{tabular}

Since the $G C I$ amount for the finer grid $\left(G C I_{21}\right)$ is small compared to the coarser grid $\left(G C I_{32}\right)$, it can be seen that the grid-independent solution is almost obtained and no further mesh modification is required. The computed value of $G C I_{32} / r^{p} G C I_{21}$ close to 1 indicates that the solution is within the asymptotic range of convergence. As a result, the cell size was decreased from 0.65 to $0.55 \mathrm{~cm}$ and the mesh including a containing block with a cell size of $1.3 \mathrm{~cm}$ and a nested block of $0.65 \mathrm{~cm}$ was selected (see Figure 4). 
To compute the allowed time-step size, a stability criterion similar to the Courant number was adopted [37]. During the repeat, the time-step size was checked by the stability and convergence criteria, which cause time steps between 0.001 and $0.0016 \mathrm{~s}$. The steady state convergence of the solutions during the simulations was controlled through monitoring the flow discharge changes at the inlet and outlet boundaries conditions. Figure 5 shows that $t=16 \mathrm{~s}$ is suitable to reach a near steady state for the adopted two discharges, i.e., $Q=0.03$ and $0.045 \mathrm{~m}^{3} / \mathrm{s}$. The computational time for the simulations was between 14 and $18 \mathrm{~h}$ using a personal computer with eight cores of a CPU (Intel Core i7-7700K @ 4.20 GHz and 16 GB RAM).
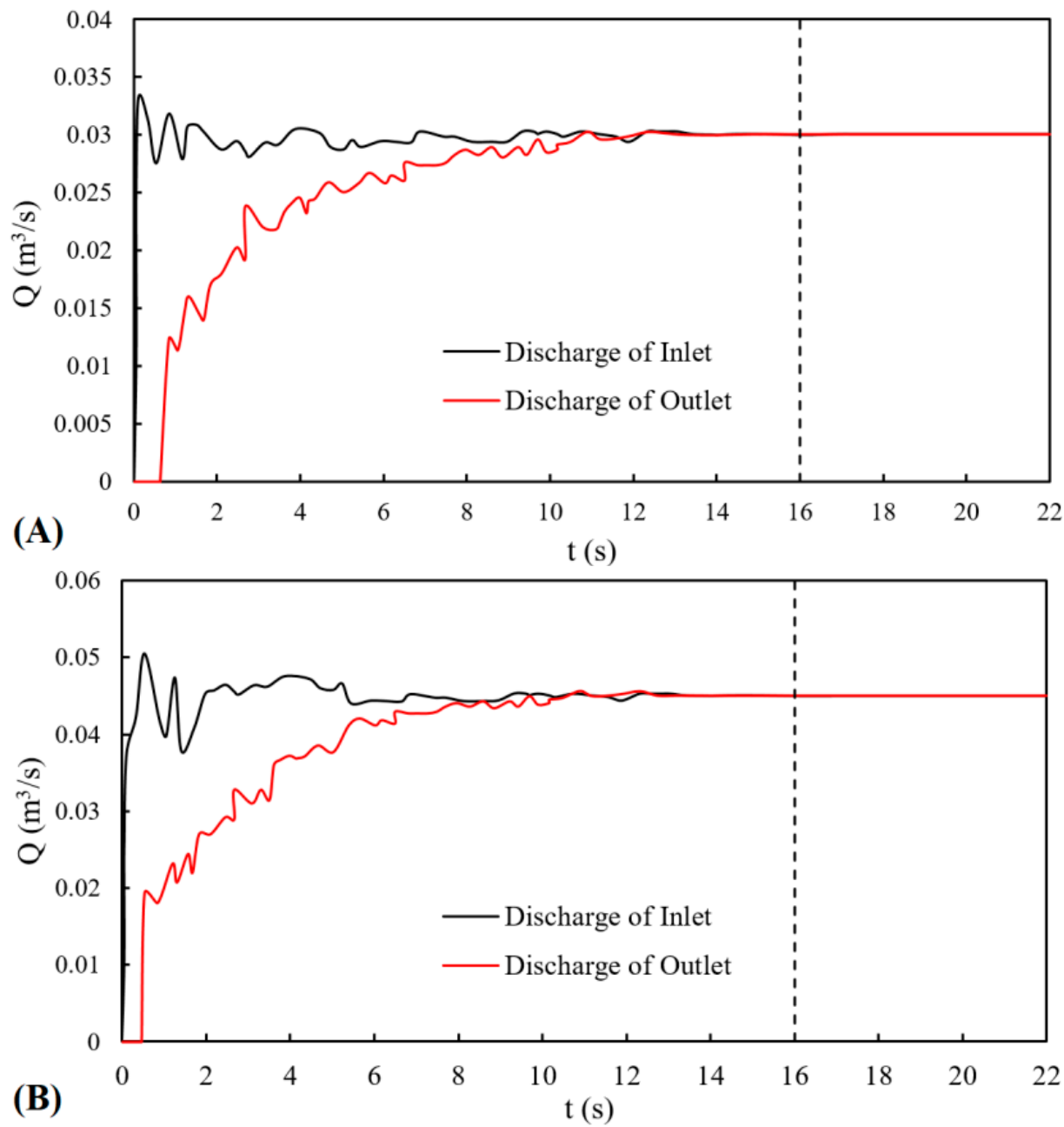

Figure 5. Time changes of the flow discharge in the inlet and outlet boundaries conditions (A): $Q=0.03 \mathrm{~m}^{3} / \mathrm{s}(\mathbf{B}): Q=0.045 \mathrm{~m}^{3} / \mathrm{s}$.

\section{Results and Discussions}

\subsection{Validity of the Numerical Model Results}

Figure 6 shows some significant time instants of the snapshots of the flow evolution of a numerical simulation of the submerged hydraulic jump on the smooth bed. The surface eddy is formed above the wall jet because of the flow near the bed. The free surface level gradually changes due to the increasing inlet velocity. The depressed water surface elevation at the end of the gate is created by the surface eddy. The stable hydraulic jump was obtained at around $t=16 \mathrm{~s}$. In this time, the water surface variations behind the gate are stable with small fluctuations. 

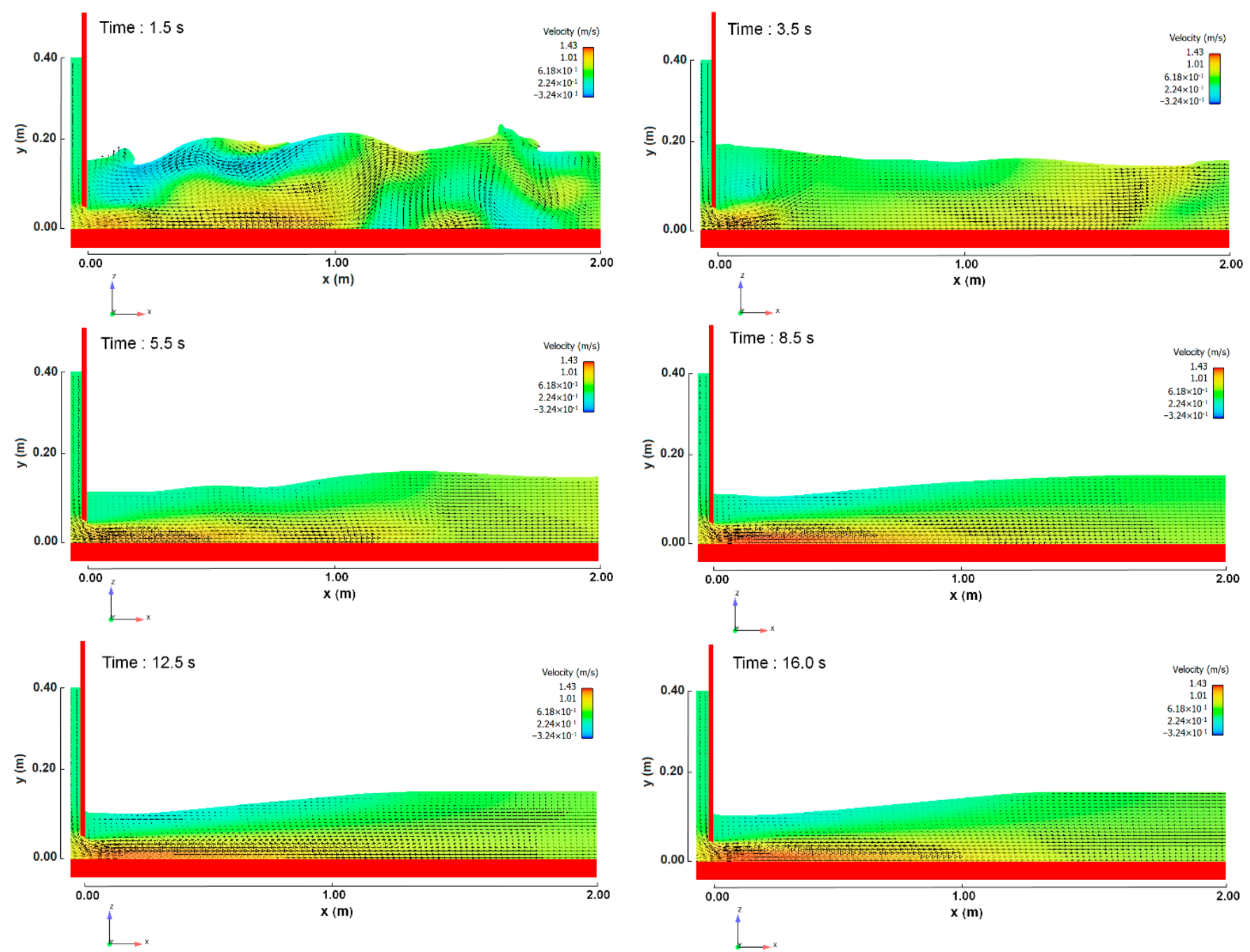

Figure 6. The evolutionary process of a submerged hydraulic jump on the smooth bed-Q $=0.03 \mathrm{~m}^{3} / \mathrm{s}$.

To check the accuracy of the FLOW-3D software, comparisons between numerical and experimental results were performed. Basic parameters including the submerged ratio and tailwater ratio $\left(y_{3} / y_{1}\right.$ and $\left.y_{4} / y_{1}\right)$ of a submerged hydraulic jump on a smooth bed and with triangular macroroughnesses with $\mathrm{T} / \mathrm{I}=0.25$ and 0.5 were extracted from the numerical simulations and plotted as shown in Figure 7. From the graphs, a strong agreement can be observed between numerical and experimental results by Ahmed et al. [20] as a function of $F r_{1}$. The overall maximum error and mean value of relative error are 8.41 and $4.83 \%$, respectively, which confirms the capability of the numerical model to predict the main properties of a submerged hydraulic jump in terms of water depths. 

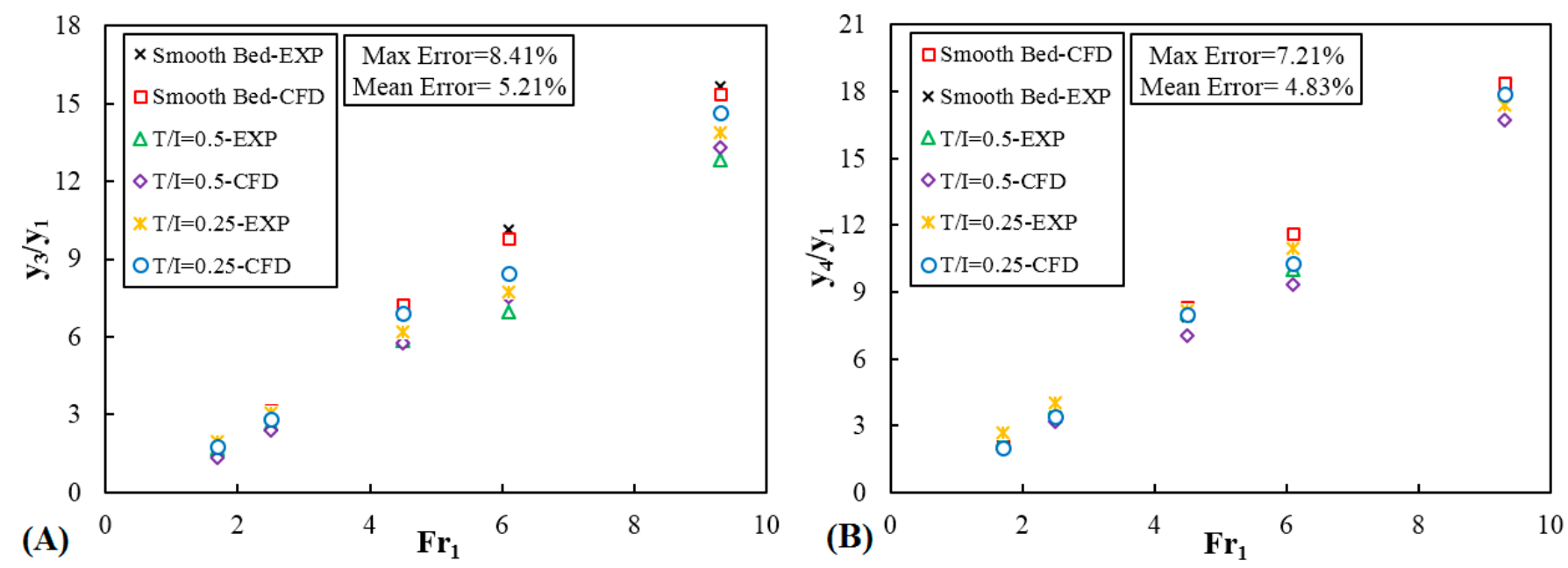

Figure 7. Numerical versus experimental basic parameters of the submerged hydraulic jump. (A): $y_{3} / y_{1} ;$ and $(\mathbf{B}): y_{4} / y_{1}$.

\subsection{Longitudinal Profile of Streamlines}

Figure 8 illustrates the longitudinal profile of the velocity vectors passing under the sluice gate for the smooth bed and in the presence of triangular macroroughnesses in a submerged hydraulic jump condition. The simulations indicate that, in the smooth bed, the hydraulic jump includes two main regions: a supercritical flow area in the developed region, where it has a big counter-clockwise circulation in the free surface roller and dissipates the hydraulic energy, and a subcritical flow area with developing open channel flow characteristics (see Figure 8A). It can also be seen that the flow pattern in the sluice gate with a triangular macroroughness in the developed and developing regions is the same in comparison to the smooth bed. In addition, triangular macroroughnesses have formed another clockwise eddy flow in the cavity region between the roughnesses (see Figure 8B).

The flow patterns in the cavity region between the triangular elements, considering the distances between the roughnesses, can be generally classified as skimming flow, wake interference and isolated roughness flow [45]. When the distances between the triangular macroroughnesses are relatively closely spaced (e.g., $T / I=1,0.5$ and 0.33 ), a clockwise eddy in the cavity occurs, where the magnitude of velocity is much smaller than the mean flow velocity in outside the cavity (see Figure 9). In the cavity region, the local mean velocity is about $10 \%$ of the mean flow velocity. In skimming flow in the cavity region, there is no significant interaction between the cavity flow and the overlying flow, and the friction coefficient is negative. This is due to the presence of a single recirculation vortex in the current case, as also noticed by [46]. The cavity may be regarded as a dead zone of fluid. With the increasing distance between triangular macroroughnesses (e.g., $T / I=0.25$ ), two eddies of different sizes formed in the cavity region. With one at the upstream and the other at the downstream corners, they interact with each other, as shown in Figure 9. In this situation, the incipient secondary vortices, placed at the upstream corner of the cavity region, mark the beginning of the wake interference flow. Changing the flow pattern in the cavity region from skimming to wake interference flow, an increase in local mean velocity from 39 to $50 \%$ of the mean flow velocity appears. In wake interference flow regimes, the vortex was unable to fill the whole cavity and started to act as a three-dimensional vortex liable to be ejected into the main flow. When the triangular macroroughnesses are well apart (e.g., $T / I=0.2$ ), isolated roughness flow occurs where a small eddy formed near the bed and the upstream vortex acts independently of the downstream vortex inside the cavity. 


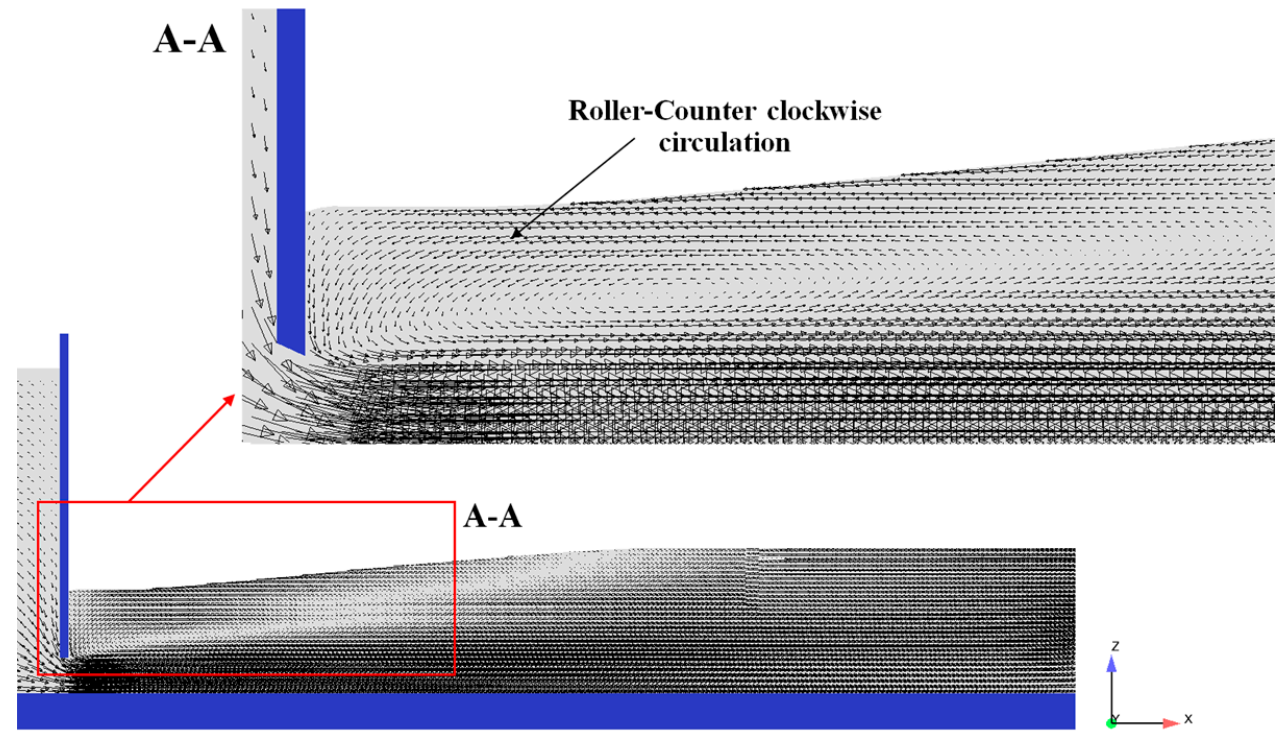

(A)

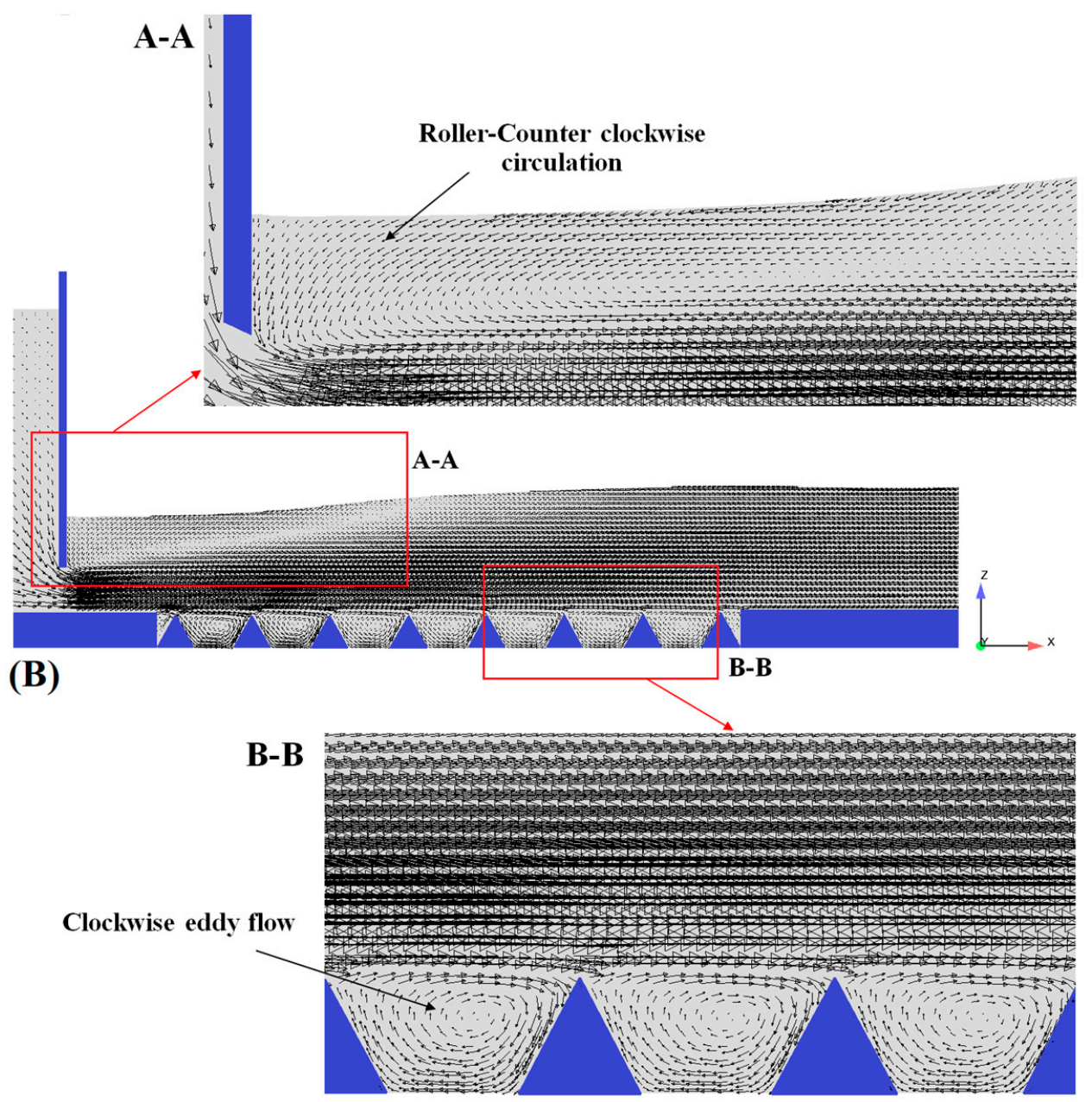

Figure 8. Velocity vector field and flow pattern through the gate in a submerged hydraulic jump condition: (A) smooth bed; (B) triangular macroroughnesses. 


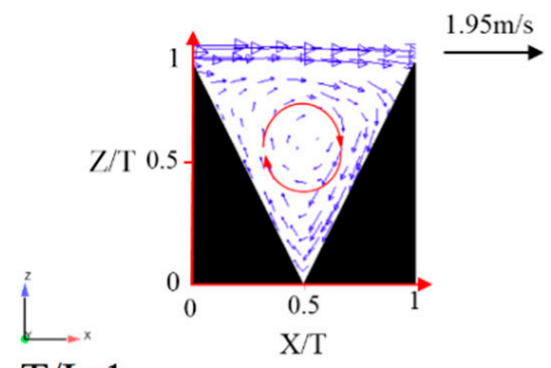

$\mathrm{T} / \mathrm{I}=1$

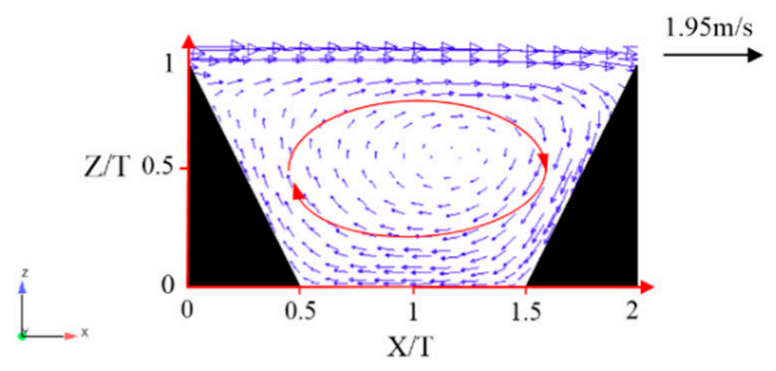

$\mathrm{T} / \mathrm{I}=0.5$
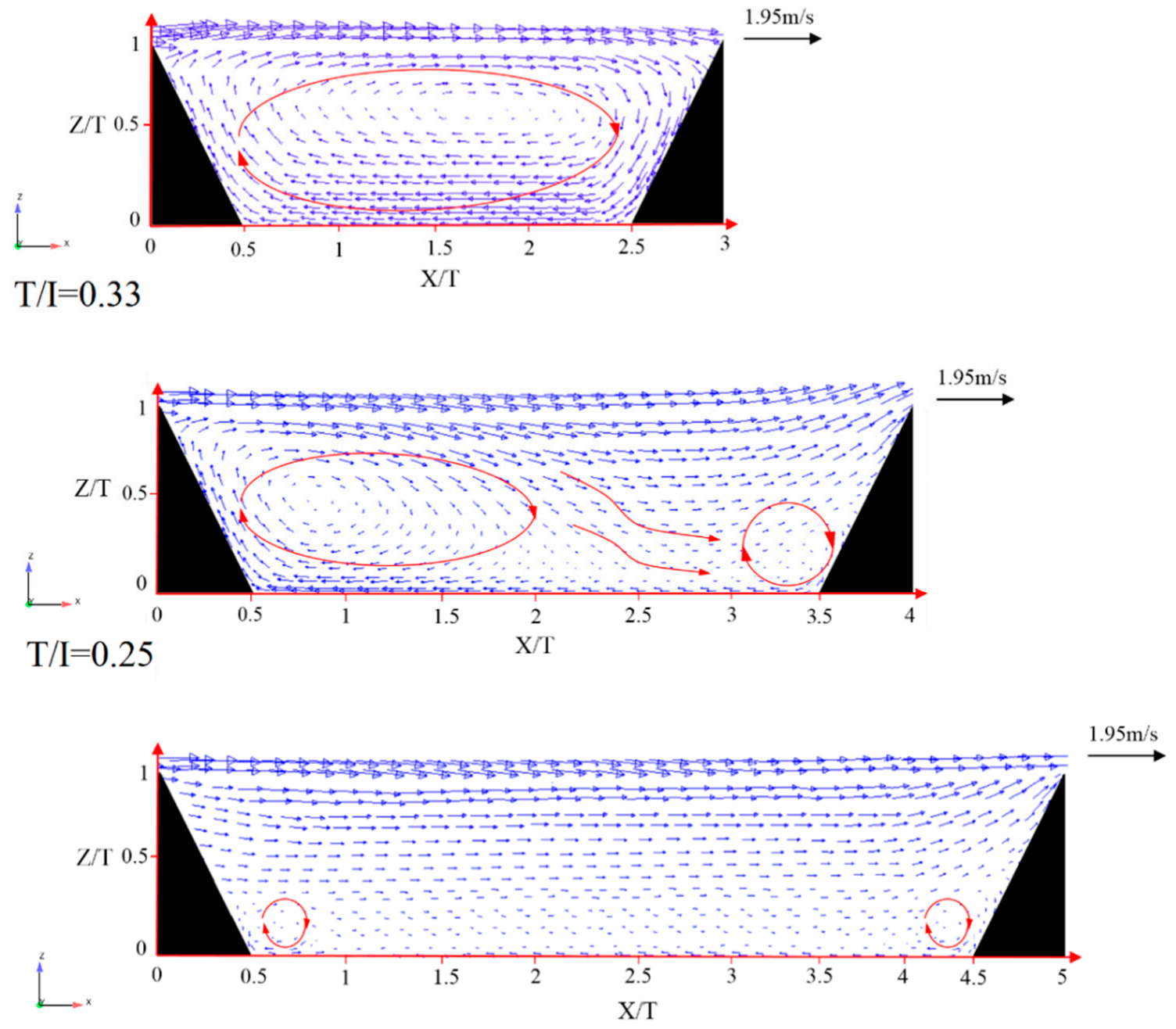

$\mathrm{T} / \mathrm{I}=0.2$

Figure 9. Velocity vector distributions in the $x-z$ plane $(y=0)$ within the cavity region.

\subsection{Velocity Profiles}

In this section, the velocity profile distributions obtained by measuring the flow velocity at different flow depths and sections on both smooth bed and triangular macroroughnesses were analyzed. The results of the present numerical simulations show that the velocity profile distributions reflect the structure of the wall jet. Hence, with increasing distance $x$ from the beginning of the submerged hydraulic jump, the maximum velocity and the boundary layer growth decrease. To compare the velocity profile distributions in various sections within the jump, $\delta$ is the value of $y$ at which the maximum velocity $\left(u_{\max }\right)$ and the length scale $(b)$ occur, which is the value of $\mathrm{y}$ at which $u=0.5 u_{\max }$ and 
$\partial \mathrm{u} / \partial \mathrm{y}<0[10,47]$ (see Figure 10). Figure 11 shows the typical velocity profiles of submerged jump on the smooth bed and triangular macroroughnesses for $T / I=1$ and 0.5 , respectively.

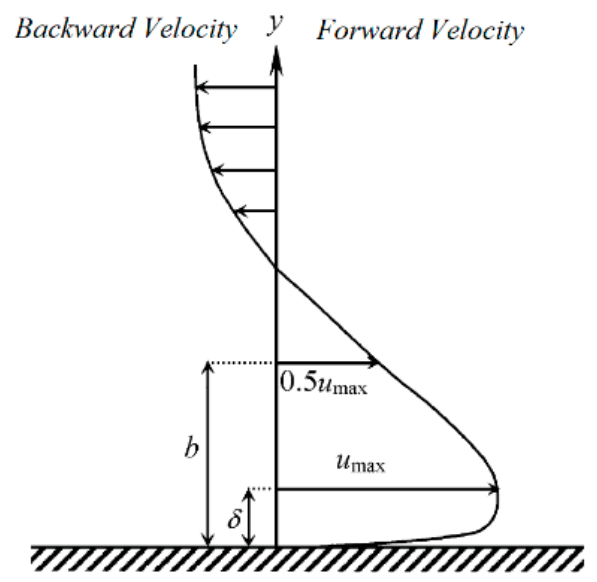

Figure 10. Typical vertical distribution of the mean horizontal velocity in a submerged hydraulic jump [46].
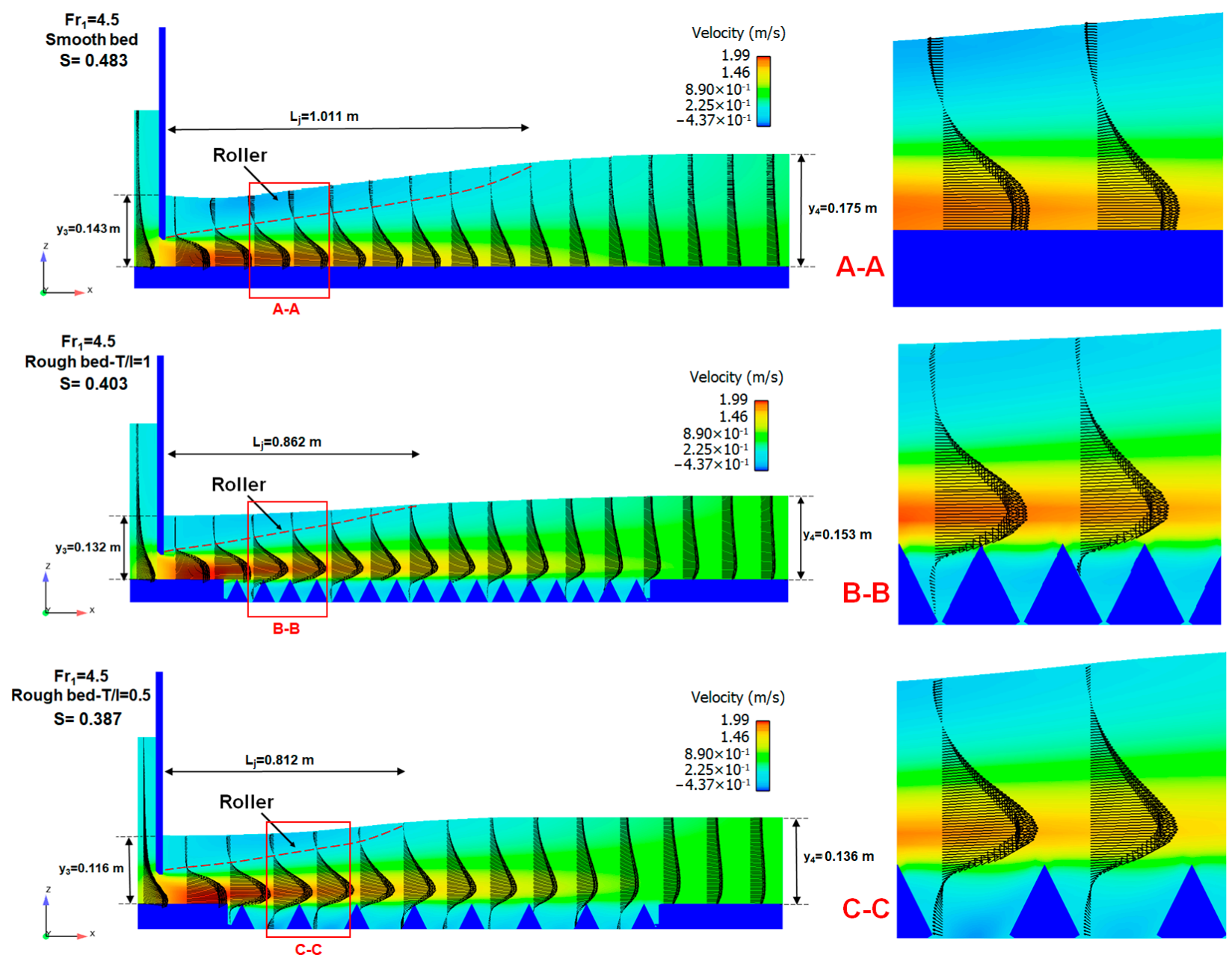

Figure 11. Typical horizontal velocity profiles in a submerged hydraulic jump on smooth bed and triangular macroroughnesses.

From the results in Figure 11, as expected, due to the contracted jet below the gate and the flow, velocities decrease at the upper section of the gate opening, since the magnitude of the mean horizontal flow velocity is bigger near the gate. Over time, reverse flow effects 
increase near the gate and then start to decrease, showing the existence of a stagnation zone on the free surface. The observations also state that the recirculation region occurs near the gate and the negative velocity in the center of the developed region is higher than near the sluice gate. The mean streamwise velocity on the free surface becomes positive in the recovering region. This description is true for both types of beds. For triangular macroroughnesses, as expected, the flow velocity near the bed strongly reduces and becomes negative between two triangles. This is due to a clockwise recirculation zone that exists the space between two macroroughnesses (see Figure 8). Despite a clockwise recirculation, the length of the submerged jump, the submerged depth, and the tailwater depth decrease by about 19.68, 20.87 and $23.34 \%$ as a mean, respectively. In Figure 12, the velocity distributions are presented at three sections during the submerged hydraulic jump. These sections are the same for each arrangement of roughness and were measured on top of the roughness elements, i.e., $y=0$. The values of $x$ and $L_{j s-s}$ represent the distance from the sluice gate and hydraulic jump length from the smooth bed, respectively.
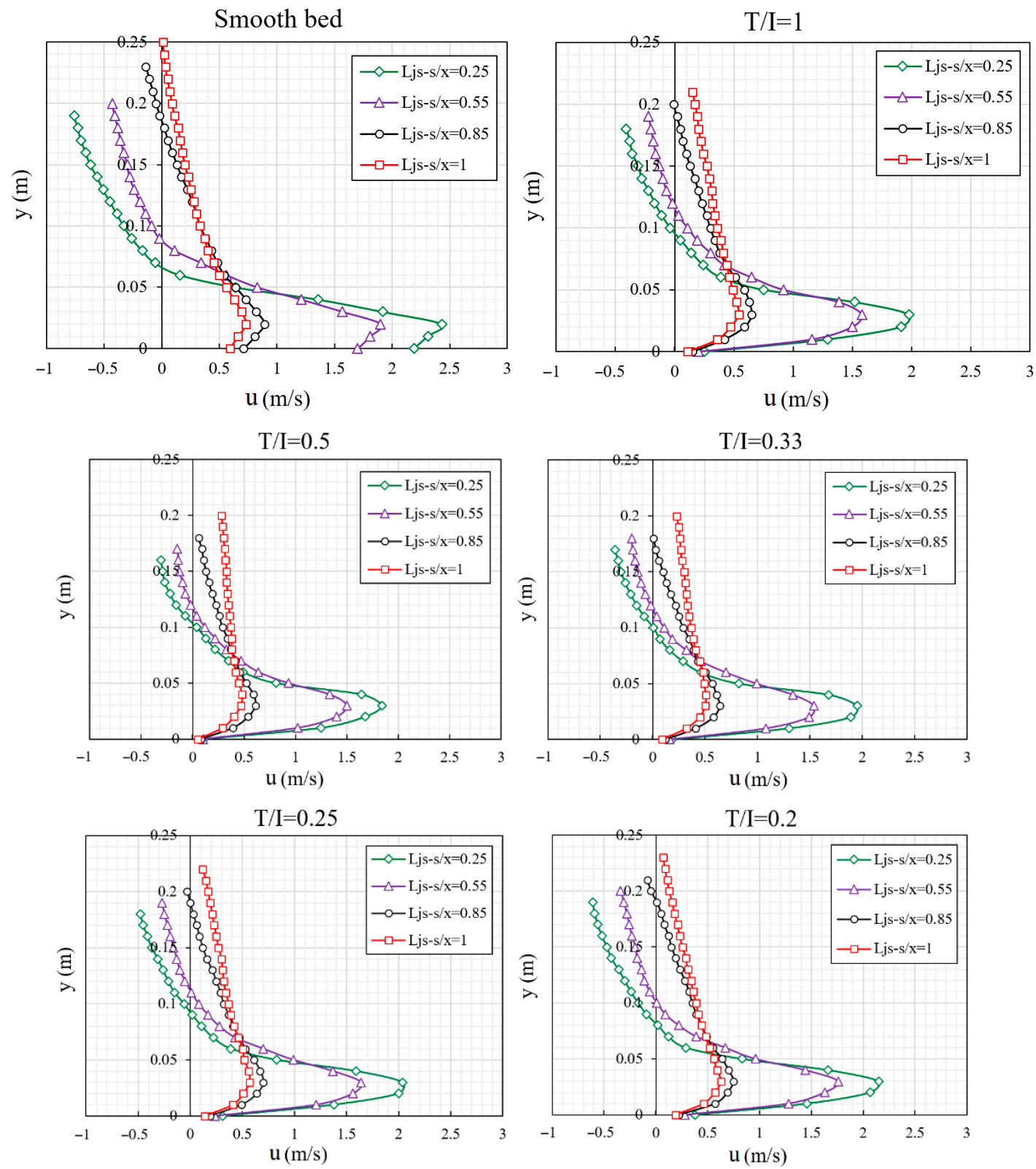

Figure 12. Horizontal velocity distribution at different distances from the sluice gate for the different $T / I$ for $F r_{1}=6.1$. 
When the distance between the triangular macroroughnesses is long enough, the velocity distribution has recovered by the time that the flow arrives at the next roughness. However, in the short distance, the flow arrives at the next roughness without adequate recovery of the velocity distribution. Hence, with decreasing distance between the macroroughnesses, the rate of increase in the frictional coefficient decreases. As shown in Figure 13, the main velocity in the downstream of each macroroughnesses is low and usually negative. Then, it gradually increases further downstream while the main velocity increases markedly in the region upstream of the macroroughnesses. By comparing the distance between the macroroughnesses, the main velocity at $T / I=0.25$ is bigger than $T / I=0.50$, despite the inlet Froude number $\left(F r_{1}\right)$ being the same. The reason can be explained by the fact that the mean velocity cannot be fully developed in a shorter distance between macroroughnesses.

$\mathrm{Fr}_{1}=6.1$ $\mathrm{T} / \mathrm{I}=0.25, \mathrm{~S}=0.394$

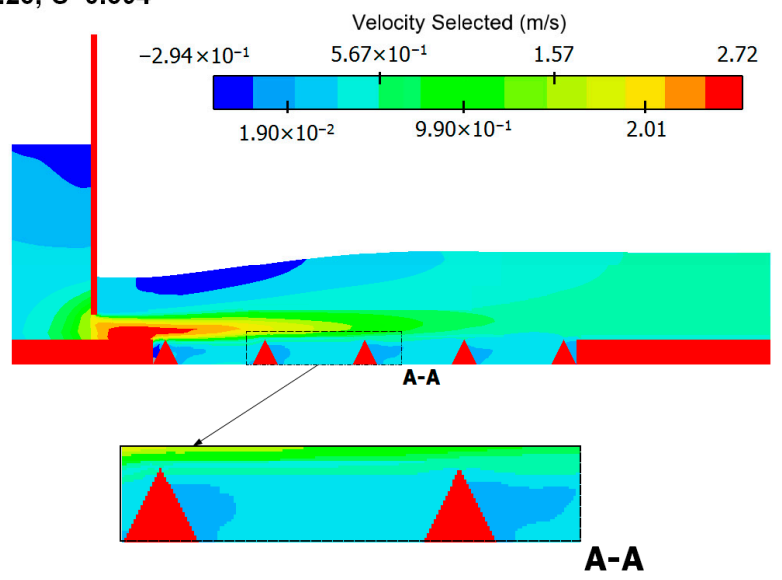

$\mathrm{Fr}_{1}=6.1$ $\mathrm{T} / \mathrm{l}=0.5, \mathrm{~S}=0.362$

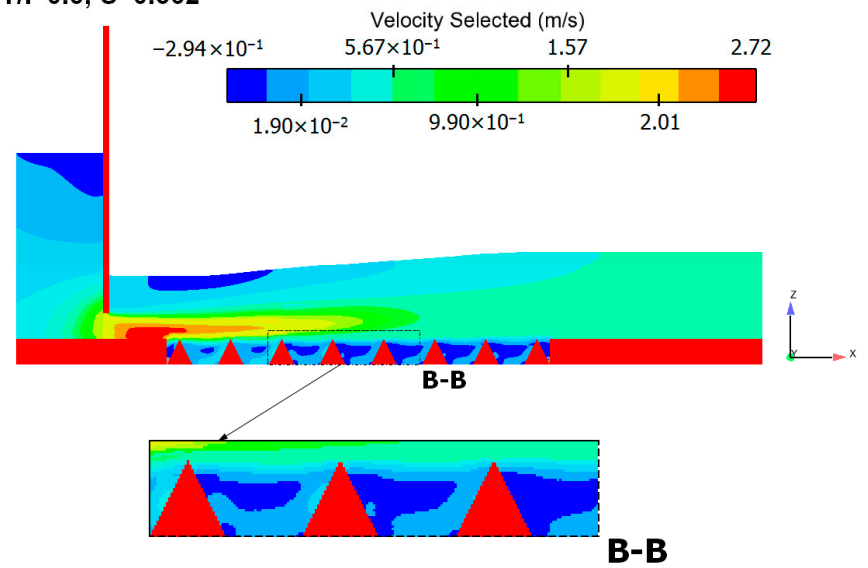

Figure 13. Stream-wise velocity distribution for the triangular macroroughnesses with $T / I=0.5$ and 0.25.

It can be observed from Figure 13 that in the developed region with triangular macroroughnesses, the size of the recirculating zone reduces and does not reach the sluice gate due to the interaction with the vortex of the vertical axis. On the opposite, the region occupied by the forward velocity increases close to the sluice gate and decreases the backward velocity in the middle of the recirculating zone. Figure 14 presents a consolidated plot of all the data simulation for the horizontal velocity distribution in the submerged hydraulic jump given by the ratio of $y / b$ versus $u / u_{\max }$. The simulations are compared with the classical jet wall and the data from experiments on submerged and free hydraulic jumps conducted by Pourabdollah et al. [48] and Ead and Rajaratnam [10], respectively. It is observed that the velocity profiles in the forward flow are similar for all the Froude numbers and the change in distance between the macroroughnesses. However, they are somewhat different from the profile for the classical jet wall, which is a plane turbulent jet wall growing in a large ambient $[49,50]$. Additionally, the maximum flow velocity of the submerged hydraulic jump occurred at a less depth compared to a previous study on a free hydraulic jump conducted by Ead and Rajaratnam [10]. Increasing the distance between the macroroughnesses will reduce the position of maximum velocity, indicating the reduction in the thickness of the inner layer $(\delta)$ of the horizontal velocity distribution. 


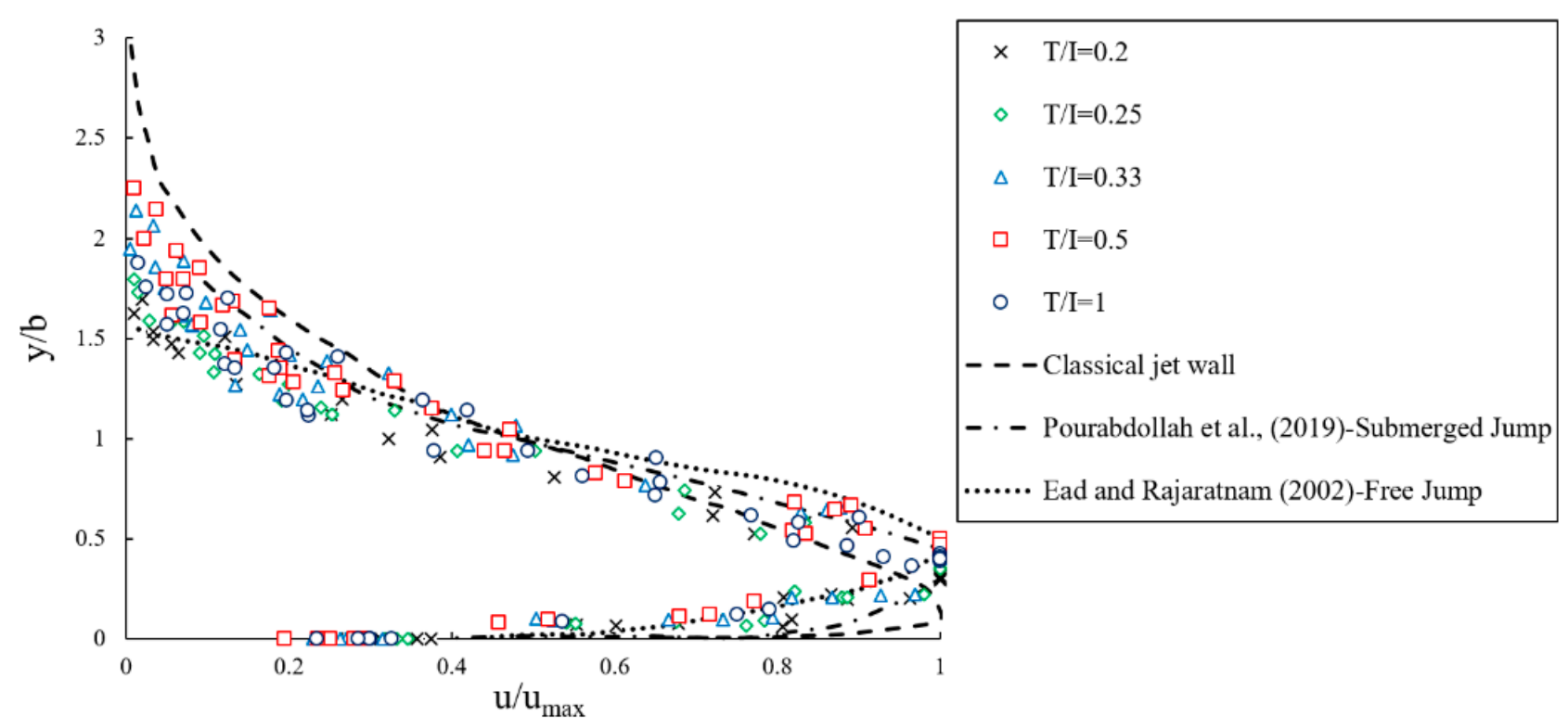

Figure 14. Dimensionless horizontal velocity distribution in the submerged hydraulic jump for different Froude numbers in triangular macroroughnesses.

The spatial variation of values $\left(u_{\max } / u_{1}\right)$ and $\left(\delta / y_{1}\right)$ in submerged jumps over smooth bed and macroroughnesses are illustrated in Figure 15. In this figure, $\mathrm{X}$ represents the distance related to start of the hydraulic jump. The results are compared with the data reported by Ghaderi et al. [17] and Abbaspour et al. [12] in free jumps on a rough bed, Shekari et al. [51] and Pourabdollah et al. [48] in submerged jumps on a smooth bed. In the macroroughnesses, the maximum flow velocity before the jump is more than in the smooth bed. However, after the jump, these values are higher in the smooth bed for the submerged jump. By increasing the distance between the roughnesses, the maximum flow velocity is increased. In the macroroughnesses, the ratio $\left(u_{\max } / u_{1}\right)$ at a specified $X$ in the submerged jump is higher than in the free jump. This finding agrees with a previous study by Pourabdollah et al. [48]. For both types of bed (smooth bed and macroroughnesses), the maximum velocity distance from the bed is decreased due to the increasing depth and eddy flow. The results of the present study are in good agreement with the data reported by Abbaspour et al. [12] and Pourabdollah et al. [48].
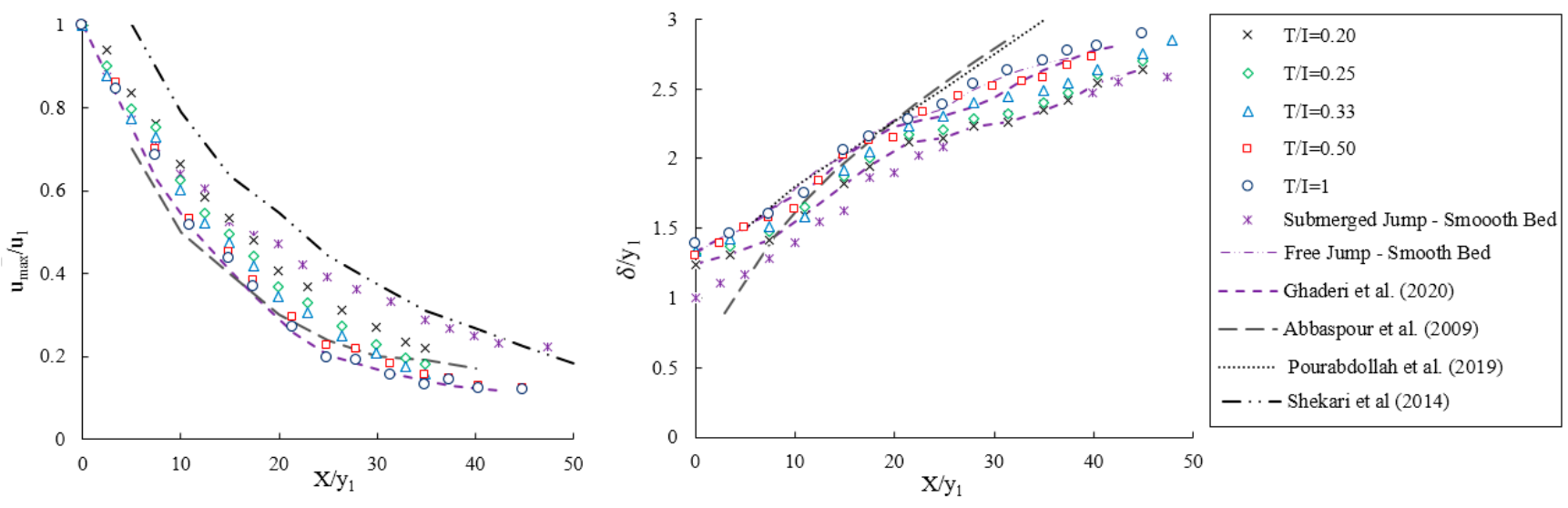

Figure 15. Spatial variations of $\left(u_{\max } / u_{1}\right)$ and $\left(\delta / y_{1}\right)$. 


\subsection{Bed Shear Stress}

The application of the macroroughnesses is to increase the bed shear stress [10]. The bed shear stress coefficient $(\varepsilon)$ is calculated as shown in Equation (15) (from Rajaratnam [24]):

$$
\varepsilon=\frac{F_{\tau}}{0.5 \gamma b y_{1}^{2}}
$$

where $\gamma$ is the specific weight of water, $F_{\tau}$ is shear force per unit width. This quantity can be obtained using Equation (16):

$$
F_{\tau}=\left(P_{1}-P_{2}\right)+\left(M_{1}-M_{2}\right)
$$

Here, $P_{1}, P_{2}, M_{1}$ and $M_{2}$ are the pressure and momentum before and after the jump, respectively [52]. The bed shear stress coefficient $(\varepsilon)$ for the hydraulic jump on the smooth bed and macroroughnesses was calculated on the basis of the following equations, respectively [10]:

$$
\begin{gathered}
\varepsilon=0.16 F r_{1}^{2}-0.8 F r_{1}+1 \\
\varepsilon=\left(F r_{1}-1\right)^{2}
\end{gathered}
$$

The value of $(\varepsilon)$ was obtained by Equation (15) and it was plotted against the inlet Froude number $\left(F r_{1}\right)$ in Figure 16. The results of this study were compared with prior research data by Ahmed et al. [20] and their experimental data.

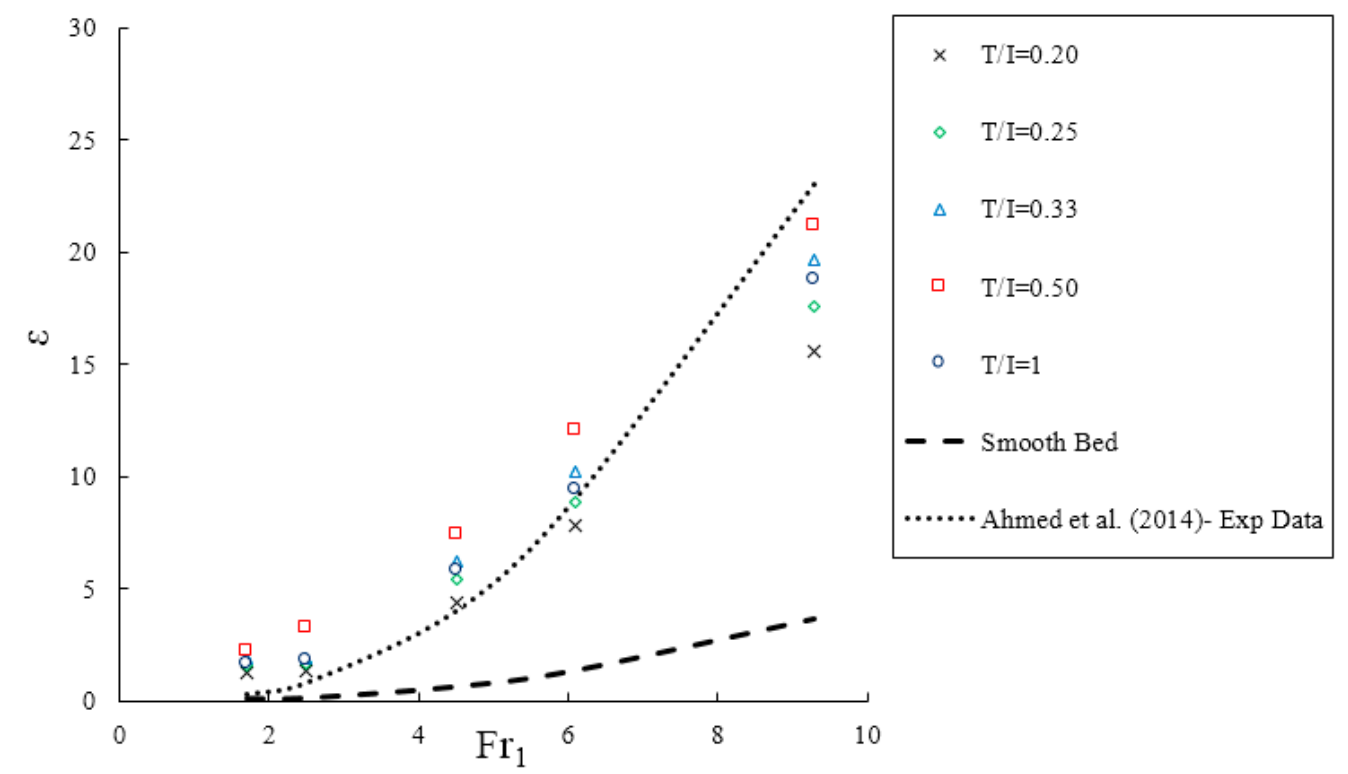

Figure 16. The shear stress coefficient $(\varepsilon)$ versus the inlet Froude number $\left(F r_{1}\right)$.

According to Figure 16, increasing the inlet Froude number $\left(F r_{1}\right)$, the shear stress coefficient $(\varepsilon)$ increases. The value of $\varepsilon$ of the submerged jump on the triangular macroroughnesses is greater than the one obtained for smooth bed. With the increasing distance of roughness elements, the highest and lowest shear stress occurs at $T / I=0.50$ and 0.20 , respectively, in comparison to other ratios. It can be stated that there was a generally good agreement between the simulations of this study and the results reported by Ahmed et al. [20]. In general, based on the results drawn from the present study, the following equation for the bed shear stress coefficient on the triangular macroroughnesses was obtained:

$$
\varepsilon=0.523 F r_{1}^{1.605} \rightarrow\left(R^{2}=0.957\right)
$$




\subsection{Turbulent Kinetic Energy (TKE) and Energy Loss}

The turbulent kinetic energy (TKE) is a function of the average velocity values in the three directions $(x, y, z)$ and is an important index to reflect the energy loss between two sections of the flow. TKE is characterized by measuring the root-mean-square of the velocity fluctuations [1]. Considering the continuous values of velocities in the flow direction $\left(u_{1}, u_{2}, u_{3}, \ldots, u_{n}\right)$, the value of the root mean square velocity, $u_{r m s}$, is obtained as

$$
u_{r m s}=\sqrt{1 / n\left(u_{1}^{2}+u_{2}^{2}+u_{3}^{2}+\ldots+u_{n}^{2}\right)}
$$

Then, TKE is calculated as

$$
T K E=1 / 2\left(u_{r m s}^{2}+v_{r m s}^{2}+w_{r m s}^{2}\right)
$$

When the energy loss is fierce (or insufficient) for turbulent flow, the values of TKE would increase up (or decrease down). The longitudinal sections are adopted to describe the TKE variation. As shown in Figure 17A, the turbulence region on a smooth bed is created with the distance from a sluice gate and occurs near free surface roller area, thus resulting in hysteretic energy loss and a wide sweep region on the length of the smooth bed. Whereas on the triangular macroroughnesses, the region of turbulence begins near a sluice gate with greater intensity and a limited sweep region that is the result of a counterclockwise circulating in free surface roller and clockwise eddy flow in the space between the roughness. By increasing the distance between the roughnesses, the intensity of the turbulence region is reduced.

Observe also from Figure 17A,B that the peak of the TKE increases in elevation as $Y$ decreases from the centerline of the channel $(Y / 2)$; indeed, the overall values of TKE close to the wall $(Y / 6)$ are smaller than in the centerline section $(Y / 2)$. This is essentially due to the separated boundary-layer from the returning flow near the free surface, which is the effect in the intensity of TKE and discussed by de Dios et al. [53]. The energy loss through the submerged hydraulic jump $\left(E_{L}\right)$ is equal to the difference between the specific energy before and after the submerged jump $\left(E_{3}-E_{4}\right)$ :

$$
\frac{E_{L}}{E_{3}}=\frac{E_{3}-E_{4}}{E_{3}}=\frac{\left(y_{3}+V_{3}^{2} / 2 g\right)-\left(y_{4}+V_{4}^{2} / 2 g\right)}{\left(y_{3}+V_{3}^{2} / 2 g\right)}
$$

where $y_{3}$ and $y_{4}$ are the submerged and tailwater depths in the submerged jump, and $V_{3}$ and $V_{4}$ are the flow velocities before and after the submerged jump, respectively [48]. In Figure 18, the relative energy loss $\left(E_{L} / E_{3}\right)$ was plotted against the inlet Froude numbers $\left(F r_{1}\right)$ for smooth bed and various types of triangular macroroughnesses.

Figure 18 illustrates that $E_{L} / E_{3}$ increases with the increasing inlet Froude number $\left(F r_{1}\right)$. The results stated that, for the same Froude number, the energy loss through the jump on a triangular macroroughnesses with different ratio was greater than the smooth bed. The highest $E_{L} / E_{3}$ occurs for $T / I=0.50$ in the submerged jump compared to the values of $T / I$. The reason for this, with increasing roughness distance, is due to the fact that the vortices created between the roughness decreases and become closer to the smooth bed. The results of this study compared with the results of Pourabdollah et al. [48], showing a good agreement between numerical simulations and experimental results. The following equation allows for the prediction of the relative energy loss with a good correlation coefficient:

$$
\frac{E_{L}}{E_{3}}=-0.006 F r_{1}^{2}+0.122 F r_{1}-0.078 \rightarrow R^{2}=0.996
$$



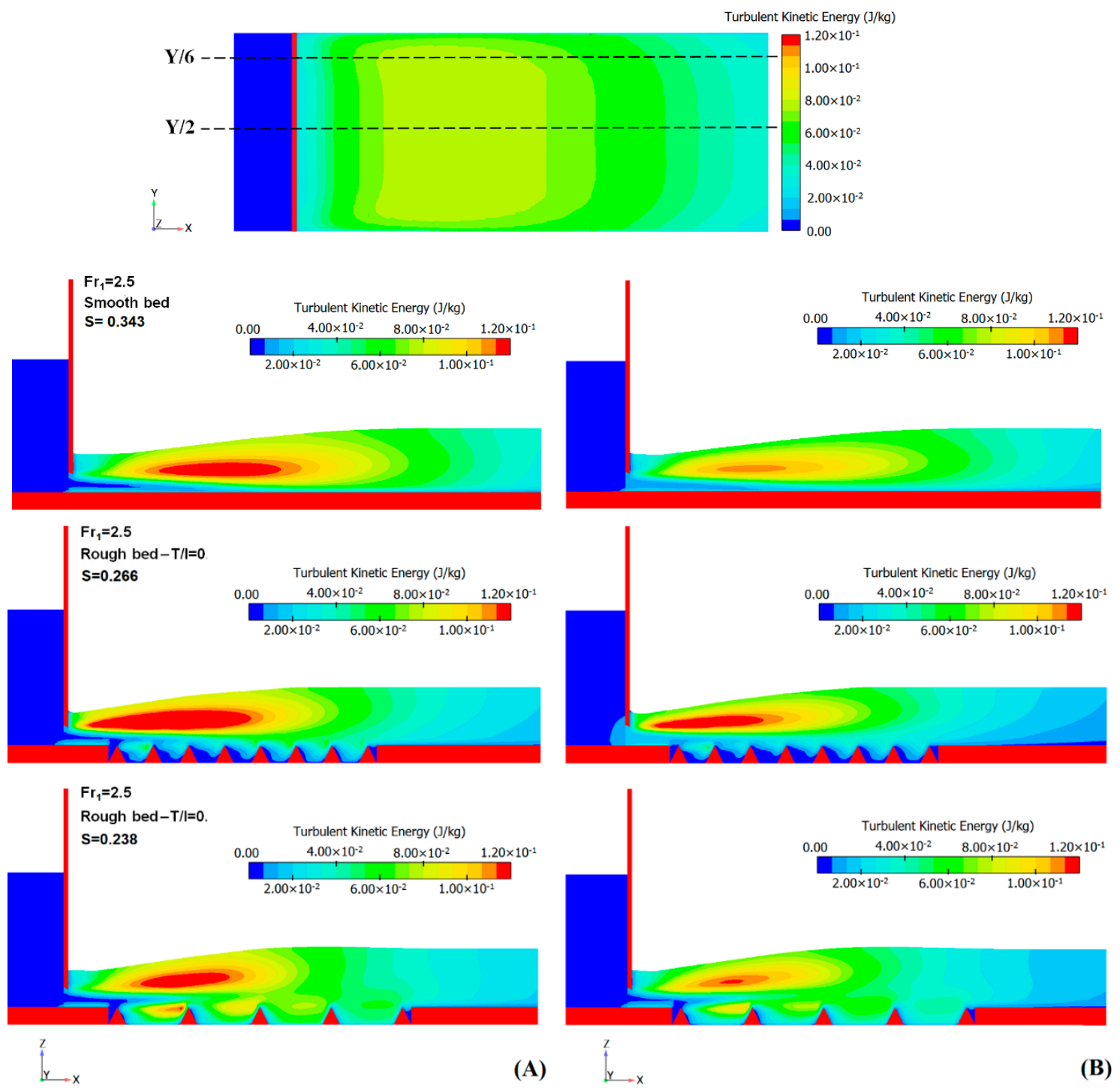

(A)

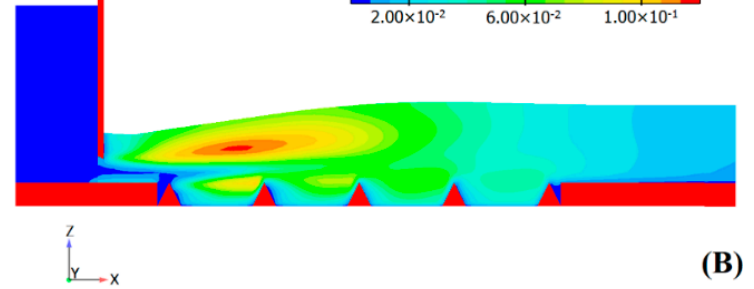

Figure 17. Longitudinal turbulent kinetic energy distribution on the smooth and triangular macroroughnesses: (A) Y/2; (B) $Y / 6$.

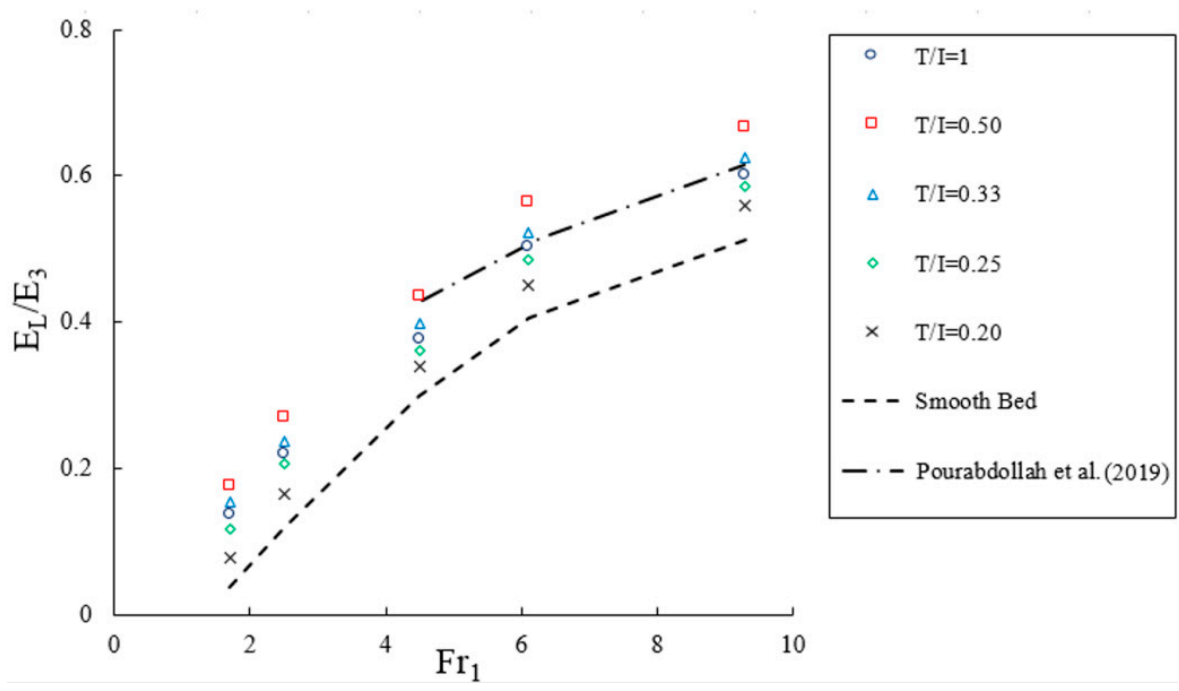

Figure 18. The energy loss $\left(E_{L} / E_{3}\right)$ of the submerged jump versus inlet Froude number $\left(F r_{1}\right)$. 


\section{Conclusions}

The present paper presented and discussed the characteristics of submerged hydraulic jump including the longitudinal profile of streamlines, flow patterns in the cavity region, horizontal velocity profiles, streamwise velocity distribution, thickness of the inner layer, bed shear stress coefficient, turbulent kinetic energy (TKE) and energy loss over triangular macroroughnesses. These characteristics were numerically investigated using the FLOW$3 \mathrm{D}^{\circledR}$ model. The volume of fluid (VOF) method to simulate free surface and the turbulence RNG $k-\varepsilon$ model are implemented. To validate the present model, comparisons between numerical simulations and experimental results were performed for the smooth bed and triangular macroroughnesses. The following results of the present study can be drawn:

- The flow patterns in the triangular macroroughnesses in the developed and developing regions are the same with smaller areas in comparison with the smooth bed in submerged hydraulic jump conditions. The triangular macroroughnesses lead to the formation of another clockwise eddy flow in the cavity region between the macroroughnesses.

- For distances equal to $T / I=1,0.5$ and 0.33 , the velocity vector distribution displays a clockwise eddy in the cavity region, where the magnitude of velocity is much smaller than the mean flow velocity. Increasing the distance between triangular macroroughnesses $(T / I=0.25$ and 0.2$)$, two eddies of different sizes are formed in the cavity region.

- When the distance between the triangular macroroughnesses is long enough, the velocity distribution has recovered by the time that the flow arrives at the next roughness. However, in the short distance, the flow arrives at the next roughness without adequate recovery of the velocity distribution. Hence, with decreasing distance between macroroughnesses, the rate of increase in the frictional coefficient decreases.

- In the triangular macroroughnesses, the maximum velocity at a specified section in the submerged jump leads to higher values than the free jump. In addition, for both types of bed (smooth and rough) in the submerged jump, the maximum velocity distance from the bed is decreased due to increasing depth and eddy flow. In the submerged jump, the boundary layer thickness is less than the free jump.

- The turbulence region on the smooth bed is created with the distance from the gate and occurs near free surface roller area, whereas on the macroroughnesses, the turbulence begins near a gate with greater intensity and limited sweep region that is the result of a counterclockwise circulating in free surface roller and clockwise eddy flow in the space between the macroroughnesses.

- The bed shear stress coefficient and energy loss of the submerged jump on the triangular macroroughnesses is larger than that found on the smooth bed that increased with the increase in inlet Froude numbers. The highest and lowest bed shear stress coefficient and energy loss occur in $T / I=0.50$ and 0.20 with the increasing distance of roughness elements compared to a smooth bed.

- The reduction in the length of the jump and the submerged and tailwater depths given by the presence of triangular macroroughnesses with near-roughness elements can be used in the design of stilling basins with a resulting decrease in their size, i.e., length and height.

Generally, CFD models are fairly well able to simulate predictions of properties of submerged jump, considering various hydraulic conditions and geometrical arrangements. Flow patterns in the cavity region, streamwise and horizontal velocity distribution, bed shear stress coefficient, TKE and the energy loss of hydraulic jump can be simulated with a numerical method. However, the study of the macroroughnesses dimension and various arrangements on the alteration of the flow field and cavity flow as a future work remains an issue to be faced. 
Author Contributions: Conceptualization, A.G., M.D., F.A., and C.A.; methodology, A.G., M.D., F.A., and C.A.; software, A.G. and M.D.; validation, A.G., M.D. and F.A.; formal analysis, A.G., M.D., and F.A.; investigation, A.G., M.D., F.A., and C.A.; writing-original draft preparation, A.G., F.A., and C.A.; writing-review and editing, A.G., F.A., and C.A.; supervision, A.G. and F.A.; project administration, A.G. All authors have read and agreed to the published version of the manuscript.

Funding: This research received no external funding.

Institutional Review Board Statement: Not applicable.

Informed Consent Statement: Not applicable.

Data Availability Statement: Data is contained within the article.

Conflicts of Interest: The authors declare no conflict of interest.

\section{References}

1. White, F.M. Viscous Fluid Flow, 2nd ed.; McGraw-Hill University of Rhode Island: Montreal, QC, Canada, 1991.

2. Launder, B.E.; Rodi, W. The turbulent wall jet. Prog. Aerosp. Sci. 1979, 19, 81-128. [CrossRef]

3. McCorquodale, J.A. Hydraulic jumps and internal flows. In Encyclopedia of Fluid Mechanics; Cheremisinoff, N.P., Ed.; Golf Publishing: Houston, TX, USA, 1986; pp. 120-173.

4. Federico, I.; Marrone, S.; Colagrossi, A.; Aristodemo, F.; Antuono, M. Simulating 2D open-channel flows through an SPH model. Eur. J. Mech. B Fluids 2012, 34, 35-46. [CrossRef]

5. Khan, S.A. An analytical analysis of hydraulic jump in triangular channel: A proposed model. J. Inst. Eng. India Ser. A 2013, 94, 83-87. [CrossRef]

6. Mortazavi, M.; Le Chenadec, V.; Moin, P.; Mani, A. Direct numerical simulation of a turbulent hydraulic jump: Turbulence statistics and air entrainment. J. Fluid Mech. 2016, 797, 60-94. [CrossRef]

7. Daneshfaraz, R.; Ghahramanzadeh, A.; Ghaderi, A.; Joudi, A.R.; Abraham, J. Investigation of the effect of edge shape on characteristics of flow under vertical gates. J. Am. Water Works Assoc. 2016, 108, 425-432. [CrossRef]

8. Azimi, H.; Shabanlou, S.; Kardar, S. Characteristics of hydraulic jump in U-shaped channels. Arab. J. Sci. Eng. 2017, 42, 3751-3760. [CrossRef]

9. De Padova, D.; Mossa, M.; Sibilla, S. SPH numerical investigation of characteristics of hydraulic jumps. Environ. Fluid Mech. 2018, 18, 849-870. [CrossRef]

10. Ead, S.A.; Rajaratnam, N. Hydraulic jumps on corrugated beds. J. Hydraul. Eng. 2002, 128, 656-663. [CrossRef]

11. Tokyay, N.D. Effect of channel bed corrugations on hydraulic jumps. In Proceedings of the World Water and Environmental Resources Congress 2005, Anchorage, AK, USA, 15-19 May 2005; pp. 1-9.

12. Abbaspour, A.; Dalir, A.H.; Farsadizadeh, D.; Sadraddini, A.A. Effect of sinusoidal corrugated bed on hydraulic jump characteristics. J. Hydro-Environ. Res. 2009, 3, 109-117. [CrossRef]

13. Shafai-Bejestan, M.S.; Neisi, K. A new roughened bed hydraulic jump stilling basin. Asian J. Appl. Sci. 2009, 2, 436-445. [CrossRef]

14. Izadjoo, F.; Shafai-Bejestan, M. Corrugated bed hydraulic jump stilling basin. J. Appl. Sci. 2007, 7, 1164-1169. [CrossRef]

15. Nikmehr, S.; Aminpour, Y. Numerical Simulation of Hydraulic Jump over Rough Beds. Period. Polytech. Civil Eng. 2017, 64, 396-407. [CrossRef]

16. Flow Science Inc. FLOW-3D V 11.2 User's Manual; Flow Science Inc.: Santa Fe, NM, USA, 2016.

17. Ghaderi, A.; Dasineh, M.; Aristodemo, F.; Ghahramanzadeh, A. Characteristics of free and submerged hydraulic jumps over different macroroughnesses. J. Hydroinform. 2020, 22, 1554-1572. [CrossRef]

18. Elsebaie, I.H.; Shabayek, S. Formation of hydraulic jumps on corrugated beds. Int. J. Civil Environ. Eng. IJCEE-IJENS 2010, 10, 37-47.

19. Samadi-Boroujeni, H.; Ghazali, M.; Gorbani, B.; Nafchi, R.F. Effect of triangular corrugated beds on the hydraulic jump characteristics. Can. J. Civil Eng. 2013, 40, 841-847. [CrossRef]

20. Ahmed, H.M.A.; El Gendy, M.; Mirdan, A.M.H.; Ali, A.A.M.; Haleem, F.S.F.A. Effect of corrugated beds on characteristics of submerged hydraulic jump. Ain Shams Eng. J. 2014, 5, 1033-1042. [CrossRef]

21. Viti, N.; Valero, D.; Gualtieri, C. Numerical simulation of hydraulic jumps. Part 2: Recent results and future outlook. Water 2019, 11, 28. [CrossRef]

22. Gumus, V.; Simsek, O.; Soydan, N.G.; Akoz, M.S.; Kirkgoz, M.S. Numerical modeling of submerged hydraulic jump from a sluice gate. J. Irrig. Drain. Eng. 2016, 142, 04015037. [CrossRef]

23. Jesudhas, V.; Roussinova, V.; Balachandar, R.; Barron, R. Submerged hydraulic jump study using DES. J. Hydraul. Eng. 2017, 143, 04016091. [CrossRef]

24. Rajaratnam, N. The hydraulic jump as a wall jet. J. Hydraul. Div. 1965, 91, 107-132. [CrossRef]

25. Hager, W.H. Energy Dissipaters and Hydraulic Jump; Kluwer Academic Publisher: Dordrecht, The Netherlands, 1992; pp. 185-224.

26. Long, D.; Steffler, P.M.; Rajaratnam, N. LDA study of flow structure in submerged Hydraulic jumps. J. Hydraul. Res. 1990, 28, 437-460. [CrossRef] 
27. Chow, V.T. Open Channel Hydraulics; McGraw-Hill: New York, NY, USA, 1959.

28. Wilcox, D.C. Turbulence Modeling for CFD, 3rd ed.; DCW Industries, Inc.: La Canada, CA, USA, 2006.

29. Hirt, C.W.; Nichols, B.D. Volume of fluid (VOF) method for the dynamics of free boundaries. J. Comput. Phys. 1981, 39, 201-225. [CrossRef]

30. Pourshahbaz, H.; Abbasi, S.; Pandey, M.; Pu, J.H.; Taghvaei, P.; Tofangdar, N. Morphology and hydrodynamics numerical simulation around groynes. ISH J. Hydraul. Eng. 2020, 1-9. [CrossRef]

31. Choufu, L.; Abbasi, S.; Pourshahbaz, H.; Taghvaei, P.; Tfwala, S. Investigation of flow, erosion, and sedimentation pattern around varied groynes under different hydraulic and geometric conditions: A numerical study. Water 2019, 11, 235. [CrossRef]

32. Zhenwei, Z.; Haixia, L. Experimental investigation on the anisotropic tensorial eddy viscosity model for turbulence flow. Int. J. Heat Technol. 2016, 34, 186-190.

33. Carvalho, R.; Lemos Ramo, C. Numerical computation of the flow in hydraulic jump stilling basins. J. Hydraul. Res. 2008, 46, 739-752. [CrossRef]

34. Bayon, A.; Valero, D.; García-Bartual, R.; López-Jiménez, P.A. Performance assessment of Open FOAM and FLOW-3D in the numerical modeling of a low Reynolds number hydraulic jump. Environ. Model. Softw. 2016, 80, 322-335. [CrossRef]

35. Daneshfaraz, R.; Ghaderi, A.; Akhtari, A.; Di Francesco, S. On the Effect of Block Roughness in Ogee Spillways with Flip Buckets. Fluids 2020, 5, 182. [CrossRef]

36. Ghaderi, A.; Abbasi, S. CFD simulation of local scouring around airfoil-shaped bridge piers with and without collar. Sādhanā 2019, 44, 216. [CrossRef]

37. Ghaderi, A.; Daneshfaraz, R.; Dasineh, M.; Di Francesco, S. Energy Dissipation and Hydraulics of Flow over TrapezoidalTriangular Labyrinth Weirs. Water 2020, 12, 1992. [CrossRef]

38. Ghaderi, A.; Abbasi, S.; Abraham, J.; Azamathulla, H.M. Efficiency of trapezoidal labyrinth shaped stepped spillways. Flow Meas. Instrum. 2020, 72, 101711. [CrossRef]

39. Yakhot, V.; Orszag, S.A. Renormalization group analysis of turbulence. I. basic theory. J. Sci. Comput. 1986, 1, 3-51. [CrossRef] [PubMed]

40. Biscarini, C.; Di Francesco, S.; Ridolfi, E.; Manciola, P. On the simulation of floods in a narrow bending valley: The malpasset dam break case study. Water 2016, 8, 545. [CrossRef]

41. Ghaderi, A.; Daneshfaraz, R.; Abbasi, S.; Abraham, J. Numerical analysis of the hydraulic characteristics of modified labyrinth weirs. Int. J. Energy Water Resour. 2020, 4, 425-436. [CrossRef]

42. Alfonsi, G. Reynolds-averaged Navier-Stokes equations for turbulence modeling. Appl. Mech. Rev. 2009, 62. [CrossRef]

43. Abbasi, S.; Fatemi, S.; Ghaderi, A.; Di Francesco, S. The Effect of Geometric Parameters of the Antivortex on a Triangular Labyrinth Side Weir. Water 2021, 13, 14. [CrossRef]

44. Celik, I.B.; Ghia, U.; Roache, P.J. Procedure for estimation and reporting of uncertainty due to discretization in CFD applications. J. Fluids Eng. 2008, 130, 0780011-0780013.

45. Khan, M.I.; Simons, R.R.; Grass, A.J. Influence of cavity flow regimes on turbulence diffusion coefficient. J. Vis. 2006, 9, 57-68. [CrossRef]

46. Javanappa, S.K.; Narasimhamurthy, V.D. DNS of plane Couette flow with surface roughness. Int. J. Adv. Eng. Sci. Appl. Math. 2020, 1-13. [CrossRef]

47. Nasrabadi, M.; Omid, M.H.; Farhoudi, J. Submerged hydraulic jump with sediment-laden flow. Int. J. Sediment Res. 2012, 27, 100-111. [CrossRef]

48. Pourabdollah, N.; Heidarpour, M.; Abedi Koupai, J. Characteristics of free and submerged hydraulic jumps in different stilling basins. In Water Management; Thomas Telford Ltd.: London, UK, 2019; pp. 1-11.

49. Rajaratnam, N. Turbulent Jets; Elsevier Science: Amsterdam, The Netherlands, 1976.

50. Aristodemo, F.; Marrone, S.; Federico, I. SPH modeling of plane jets into water bodies through an inflow/outflow algorithm. Ocean Eng. 2015, 105, 160-175. [CrossRef]

51. Shekari, Y.; Javan, M.; Eghbalzadeh, A. Three-dimensional numerical study of submerged hydraulic jumps. Arab. J. Sci. Eng. 2014, 39, 6969-6981. [CrossRef]

52. Khan, A.A.; Steffler, P.M. Physically based hydraulic jump model for depth-averaged computations. J. Hydraul. Eng. 1996, 122, 540-548. [CrossRef]

53. De Dios, M.; Bombardelli, F.A.; García, C.M.; Liscia, S.O.; Lopardo, R.A.; Parravicini, J.A. Experimental characterization of three-dimensional flow vortical structures in submerged hydraulic jumps. J. Hydro-Environ. Res. 2017, 15, 1-12. [CrossRef] 